\title{
Experimental Validation of the Dynamic Inertia Measurement Method to find the Mass Properties of an Iron Bird Test Article
}

\author{
Alexander W. Chin ${ }^{1}$, Claudia Y. Herrera ${ }^{2}$, and Natalie D. Spivey ${ }^{3}$ \\ NASA Armstrong Flight Research Center, Edwards, California 93523 \\ William A. Fladung ${ }^{4}$ and David Cloutier ${ }^{5}$ \\ ATA Engineering, San Diego, California 92128
}

\begin{abstract}
The mass properties of an aerospace vehicle are required by multiple disciplines for the analysis and prediction of flight behavior. Pendulum oscillation methods have been developed and employed for almost a century as a means to measure mass properties; however, oscillation methods are costly, time consuming, and risky. The National Aeronautics and Space Administration (NASA) Armstrong Flight Research Center has been investigating the Dynamic Inertia Measurement, or DIM, method as a possible alternative to oscillation methods. The DIM method uses ground test techniques that are applied to aerospace vehicles during modal surveys. Ground vibration tests would require minimal additional instrumentation and time to apply the DIM method. The DIM method has been validated on small test articles but has not yet been fully proven on large aerospace vehicles. The NASA Armstrong Flight Research Center designed and fabricated a simple test article that consisted of two I-beams and was comparable in mass and scale to a fighter-size aircraft. The DIM method was implemented to measure the mass properties of the test article, as were then the conventional pendulum oscillation methods, to compare results, level of effort, and costs. The DIM method showed favorable results for the center of gravity and moments of inertia; however, the products of inertia showed appreciable disagreement with analytical predictions. The analyses performed to derive mass properties estimations using the DIM method are reported. In addition, recommendations and considerations for further development of the DIM method are presented.
\end{abstract}

\section{Nomenclature}

a $\quad=$ measured rigid body responses

â $\quad=$ calculated rigid body responses

AFRC $=$ Armstrong Flight Research Center

$\mathrm{CAD}=$ computer-aided design

$\mathrm{CG}=$ center of gravity

$\mathrm{CMIF}=$ complex mode indicator function

Crit $=$ critical

DACS $=$ data acquisition control system

diff $=$ difference

DIM = dynamic inertia measurement

DOF $=$ degree of freedom

ETA $=$ engineering test article

\footnotetext{
1 Aerospace Engineer, NASA Armstrong, Aerostructures Branch/4820, Senior Member AIAA; alexander.w.chin@,nasa.gov

${ }^{2}$ Aerospace Engineer, NASA Armstrong, Aerostructures Branch/4820, Member AIAA; claudia.herrera-1@nasa.gov

${ }^{3}$ Aerospace Engineer, NASA Armstrong, Aerostructures Branch/4820, Member AIAA; natalie.d.spivey@,nasa.gov

${ }^{4}$ Senior Technical Advisor, ATA Engineering, Inc., 13290 Evening Creek Dr. South, Ste. 250, bfladung@ata-e.com

${ }^{5}$ Project Engineer, ATA Engineering, Inc., 13290 Evening Creek Dr. South, Ste. 250, dave.cloutier@ata-e.com
} 


\begin{tabular}{|c|c|c|}
\hline $\mathrm{F}$ & $=$ & force \\
\hline FRF & $=$ & frequency response function \\
\hline $\mathrm{F}_{\mathrm{x}}$ & $=$ & force in $\mathrm{x}$-axis \\
\hline $\mathrm{F}_{\mathrm{y}}$ & $=$ & force in $y$-axis \\
\hline $\mathrm{F}_{\mathrm{z}}$ & $=$ & force in $\mathrm{z}$-axis \\
\hline g & $=$ & gravitational acceleration \\
\hline GVT & $=$ & ground vibration test \\
\hline $\mathrm{Hz}$ & $=$ & Hertz \\
\hline I & $=$ & inertia matrix \\
\hline $\mathrm{I}_{\mathrm{xx}}$ & $=$ & moment of inertia about the $\mathrm{x}$-axis \\
\hline $\mathrm{I}_{\mathrm{xy}}$ & $=$ & product of inertia between $\mathrm{x}$ and $\mathrm{y}$-axis \\
\hline $\mathrm{I}_{\mathrm{xz}}$ & $=$ & product of inertia between $\mathrm{x}$ and $\mathrm{z}$-axis \\
\hline $\mathrm{I}_{\mathrm{yy}}$ & $=$ & moment of inertia about the y-axis \\
\hline $\mathrm{I}_{\mathrm{yz}}$ & $=$ & product of inertia between y and z-axis \\
\hline $\mathrm{I}_{\mathrm{zz}}$ & $=$ & moment of inertia about the z-axis \\
\hline $\mathrm{I}_{\mathrm{xz}}$ & $=$ & moment of inertia about the xz-axis \\
\hline IMAT & $=$ & Interface between MATLAB, Analysis, and Test \\
\hline IMU & $=$ & inertial measurement unit T13 \\
\hline $\mathrm{L}$ & $=$ & length \\
\hline lb & $=$ & pound \\
\hline lbf & $=$ & pound force \\
\hline lbm & $=$ & pound mass \\
\hline M & $=$ & mass matrix \\
\hline $\mathrm{m}$ & $=$ & mass \\
\hline MOI & $=$ & moment of inertia \\
\hline $\mathrm{mV}$ & $=$ & millivolt \\
\hline NACA & $=$ & National Advisory Committee on Aeronautics \\
\hline NASA & $=$ & National Aeronautics and Space Administration \\
\hline $\mathrm{N}_{\mathrm{x}}$ & $=$ & moment about the $\mathrm{x}$-axis \\
\hline $\mathrm{N}_{\mathrm{y}}$ & $=$ & moment about the y-axis \\
\hline $\mathrm{N}_{\mathrm{z}}$ & $=$ & moment about the $\mathrm{z}$-axis \\
\hline POI & $=$ & product of inertia \\
\hline PSMIF & $=$ & power spectrum mode indicator function \\
\hline $\mathrm{T}$ & $=$ & period \\
\hline TRL & $=$ & technology readiness level \\
\hline $\mathrm{W}$ & $=$ & weight \\
\hline $\mathrm{X}_{\mathrm{CG}}$ & $=$ & CG location along the $\mathrm{x}$-axis \\
\hline $\mathrm{x}$ & $=$ & time or frequency \\
\hline$\ddot{\mathrm{x}}$ & $=$ & linear acceleration in $\mathrm{x}$-axis \\
\hline$Y_{\mathrm{CG}}$ & $=$ & CG location along the y-axis \\
\hline$\ddot{\mathrm{y}}$ & $=$ & linear acceleration in $y$-axis \\
\hline $\mathrm{Z}_{\mathrm{CG}}$ & $=$ & CG location along the $\mathrm{z}$-axis \\
\hline$\ddot{\mathrm{z}}$ & $=$ & linear acceleration in $\mathrm{z}$-axis $\varepsilon_{\mathrm{p}}^{2}=$ rigid body error function \\
\hline$\ddot{\theta}$ & $=$ & angular acceleration \\
\hline$\ddot{\theta}_{\mathrm{x}}$ & $=$ & angular acceleration about $\mathrm{x}$-axis \\
\hline$\ddot{\theta}_{\mathrm{y}}$ & $=$ & angular acceleration about $y$-axis \\
\hline $\begin{array}{l}\ddot{\theta}_{\mathrm{z}} \\
60 \mathrm{~K} 3 \mathrm{~S}\end{array}$ & $\begin{array}{l}= \\
=\end{array}$ & $\begin{array}{l}\text { angular acceleration about z-axis } \\
60,000 \mathrm{lb} \text { Starr Soft Support }\end{array}$ \\
\hline
\end{tabular}

\section{Introduction}

$\mathrm{T}$ HE mass properties of a vehicle include the mass, center of gravity (CG), moments of inertia (MOIs), and products of inertia (POIs). This information is important to understanding and controlling the flight dynamics of the vehicle. The mass and CG can usually be determined through a weight and balance procedure, while MOI and POI require dynamic testing. Analytical models can also provide mass properties information, but must be sufficiently 
detailed as a realistic representation of the system be accurate. As examples, vehicle modifications and changes are not always tracked in the computer aided design (CAD) analytical model; and vehicles can be acquired without their corresponding analytical models. If changes to the vehicle are not explicitly modeled, the analytical mass properties will not be accurate. Remodeling an entire vehicle, however, can be cumbersome and costly to complete. Thus, it becomes necessary to experimentally test for the mass properties of a vehicle.

Spin-balance tables can provide accurate approximations of the CG and MOI, but become increasingly difficult to use as the size of the object being tested increases. When spin-balance tables are not available or practical, pendulumbased methods are often used; however, pendulum-based methods require significant amounts of labor, materials, and time, leading to high cost and risk.

Frequency response function (FRF) testing has gained interest as an alternative methodology for determining mass properties using a ground vibration test (GVT) setup. Frequency response function testing analyzes the dynamic response of a test article and is often used to identify mode shapes and natural frequencies of objects. The Dynamic Inertia Measurement (DIM) method utilizes FRF information to determine mass properties. ${ }^{1}$

The DIM method has been in development at the University of Cincinnati and has shown success on a variety of small scale test articles such as automobile brake rotors, steel blocks, and other custom fixtures from the university. ${ }^{2,3}$ Attempts to apply the DIM method to larger test articles, however, have met with limited success. ${ }^{4}$ This paper documents efforts to mature the DIM technology for application toward full scale aerospace vehicles in conjunction with GVTs.

\section{Dynamic Inertia Measurement Background Theory}

The mass properties of an object are determined by measuring all forces and moments acting on a body and the rigid body motion caused by these forces and moments. The DIM method measures the inertia properties of an object by analyzing the FRFs measured during a GVT. The FRFs are measurements that normalize the response (acceleration and reaction force) to the excitation force in the frequency domain. A simulated free-free boundary condition GVT provides the appropriate test environment such that all the reaction forces can be measured. The advent of six degree-of-freedom (DOF) force sensors has enabled the measurement of all the reaction forces and moments on the test article. $5,6,7$

The DIM method uses the rigid body forces, moments, and linear and angular accelerations to calculate the inertia matrix. Equation 1 shows Newton's second law simplified for constant mass which defines the relationship between forces, mass, and linear accelerations.

$$
\{F\}=[M]\{\ddot{x}\}
$$

Equation 2 shows Euler's second law for defining the relationship between moments, moments and products of inertia, and angular accelerations. For this solution, the cross terms were ignored because the test articles are assumed to be rigid to an extent that the vehicle rotation rate terms were small. Note that this assumption would not hold for large, flexible structures.

$$
\{N\}=[I]\{\ddot{\theta}\}
$$

Applying the small angle assumption to the moment arms and combining the force and moment equations for six degrees of freedom yields the $6 \times 6$ mass matrix for full rigid body motion as shown in Eq. (3). All forces, moments, and accelerations are measured quantities. The forces and moments are measured from DIM-related sensors. The accelerations are measured from GVT sensors. The ten unknown terms in the mass matrix (M) are the mass (m), CG location $\left(\mathrm{X}_{\mathrm{CG}}, \mathrm{Y}_{\mathrm{CG}}, \mathrm{Z}_{\mathrm{CG}}\right)$ with respect to some point $\mathrm{P}$, moments of inertia $\left(\mathrm{I}_{\mathrm{xx}}, \mathrm{I}_{\mathrm{yy}}, \mathrm{I}_{\mathrm{zz}}\right)$ calculated about $\mathrm{P}$, and products of inertia $\left(\mathrm{I}_{\mathrm{xy}}, \mathrm{I}_{\mathrm{xz}}, \mathrm{I}_{\mathrm{yz}}\right)$ calculated about $\mathrm{P}$.

$$
\left\{\begin{array}{c}
\mathrm{F}_{\mathrm{x}} \\
\mathrm{F}_{\mathrm{y}} \\
\mathrm{F}_{\mathrm{z}} \\
\mathrm{N}_{\mathrm{x}} \\
\mathrm{N}_{\mathrm{y}} \\
\mathrm{N}_{\mathrm{z}}
\end{array}\right\}=\left[\begin{array}{cccccc}
\mathrm{m} & 0 & 0 & 0 & \mathrm{mZ}_{\mathrm{CG}} & -\mathrm{mY}_{\mathrm{CG}} \\
0 & \mathrm{~m} & 0 & -\mathrm{mZ}_{\mathrm{CG}} & 0 & \mathrm{mX}_{\mathrm{CG}} \\
0 & 0 & \mathrm{~m} & \mathrm{mY}_{\mathrm{CG}} & -\mathrm{mX}_{\mathrm{CG}} & 0 \\
0 & -\mathrm{mZ}_{\mathrm{CG}} & \mathrm{mY}_{\mathrm{CG}} & \mathrm{I}_{\mathrm{xx}} & -\mathrm{I}_{\mathrm{xy}} & -\mathrm{I}_{\mathrm{xz}} \\
\mathrm{mZ}_{\mathrm{CG}} & 0 & -\mathrm{mX}_{\mathrm{CG}} & -\mathrm{I}_{\mathrm{xy}} & \mathrm{I}_{\mathrm{yy}} & -\mathrm{I}_{\mathrm{yz}} \\
-\mathrm{mY}_{\mathrm{CG}} & \mathrm{mX}_{\mathrm{CG}} & 0 & -\mathrm{I}_{\mathrm{xz}} & -\mathrm{I}_{\mathrm{yz}} & \mathrm{I}_{\mathrm{zz}}
\end{array}\right]\left\{\begin{array}{c}
\ddot{x} \\
\ddot{y} \\
\ddot{z} \\
\ddot{\theta}_{x} \\
\ddot{\theta}_{y} \\
\ddot{\theta}_{\mathrm{z}}
\end{array}\right\}
$$


For rigid body motion, all sensors on the structure exhibit identical translational and rotational motion. A method of evaluating the error in the results is to back-expand the rigid body response to the sensors using the calculated mass matrix. The measured rigid body responses are then compared to the calculated rigid body responses. A normalized rigid body error function can then be calculated for each sensor. This normalized rigid body error can be plotted, and sensors that are displayed as outliers in comparison with the majority of the error functions can be omitted from the DIM analysis. ${ }^{2,3}$ Equation 4 shows the rigid body error function where "a" encompasses the measured rigid body responses and â encompasses the calculated rigid body responses. The function is expressed as a function of $x$, which can be time or frequency.

$$
\varepsilon_{\mathrm{p}}^{2}(\mathrm{x})=\frac{\sum_{\mathrm{k}=1}^{\mathrm{N}}\left|\mathrm{a}_{\mathrm{p}, \mathrm{k}}(\mathrm{x})-\hat{\mathrm{a}}_{\mathrm{p}, \mathrm{k}}(\mathrm{x})\right|^{2}}{\sum_{\mathrm{k}=1}^{\mathrm{N}}\left|\hat{\mathrm{a}}_{\mathrm{p}, \mathrm{k}}(\mathrm{x})\right|^{2}}
$$

\section{The Iron Bird Test Article}

Two 8500-lb 20-foot long, W14x426 steel I-beams were bolted together off-center to model the approximate mass of fighter-type aircraft. The test article which was dubbed the "iron bird;" is shown in Fig. 1. The iron bird was intentionally simple in design to ensure high reliability of its analytical mass properties. Holes were drilled into the iron bird at designated locations to attach interface ball plates that were to rest on aircraft jacks and the soft-support system. Holes were also drilled to attach any required fixture(s) for MOI pendulum testing. Steel was chosen for its rigidity and lower cost.

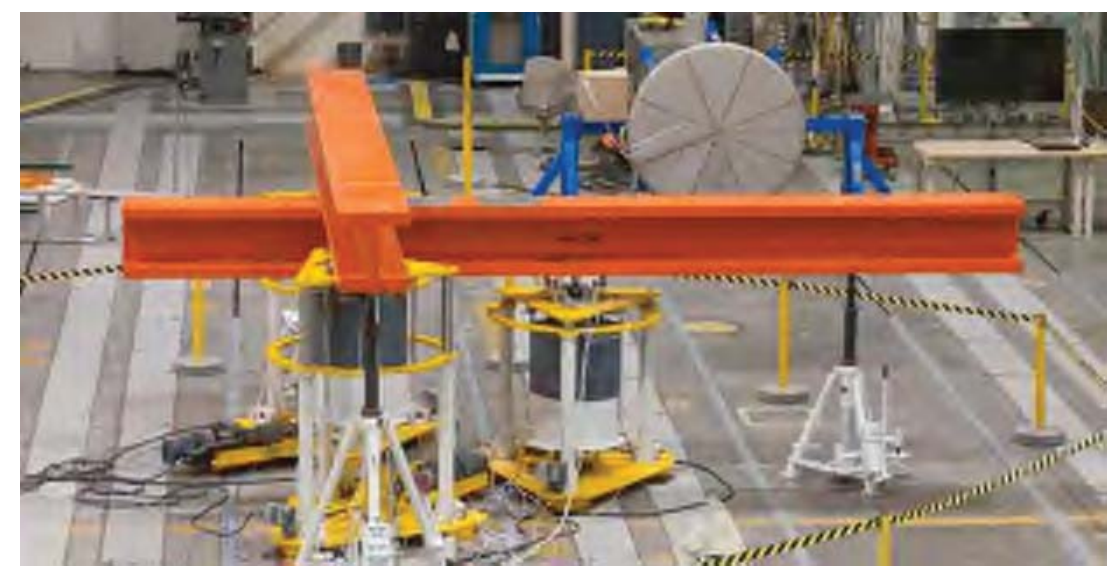

Figure 1. The iron bird test article.

The reference coordinate system used for the iron bird places the origin at the forward lower surface of the test article. Positive $\mathrm{X}$ points aft from the nose, positive $\mathrm{Y}$ points in the direction of the right wing, and positive $\mathrm{Z}$ points upward on the test article. The coordinate system is defined in the CAD model shown in Fig. 2.

\section{The Test Plan}

Three methods for determining the mass properties of the 17,000-lb iron bird test article were used for comparison. First, an analytical model was created using the solid modeling CAD program PTC Creo (Pro/ENGINEER ${ }^{\circledR}$ ) (PTC Inc., Needham, Massachusetts). Second, pendulum swing tests were performed. Third, the DIM method was implemented. These three separate and independent approaches were used to document the level of effort involved for each method. For expediency, however, the pendulum swing tests relied on the analytical vertical $\mathrm{Z}_{\mathrm{CG}}$. The DIM test obtained data completely independent of any analytical and pendulum mass properties data. 


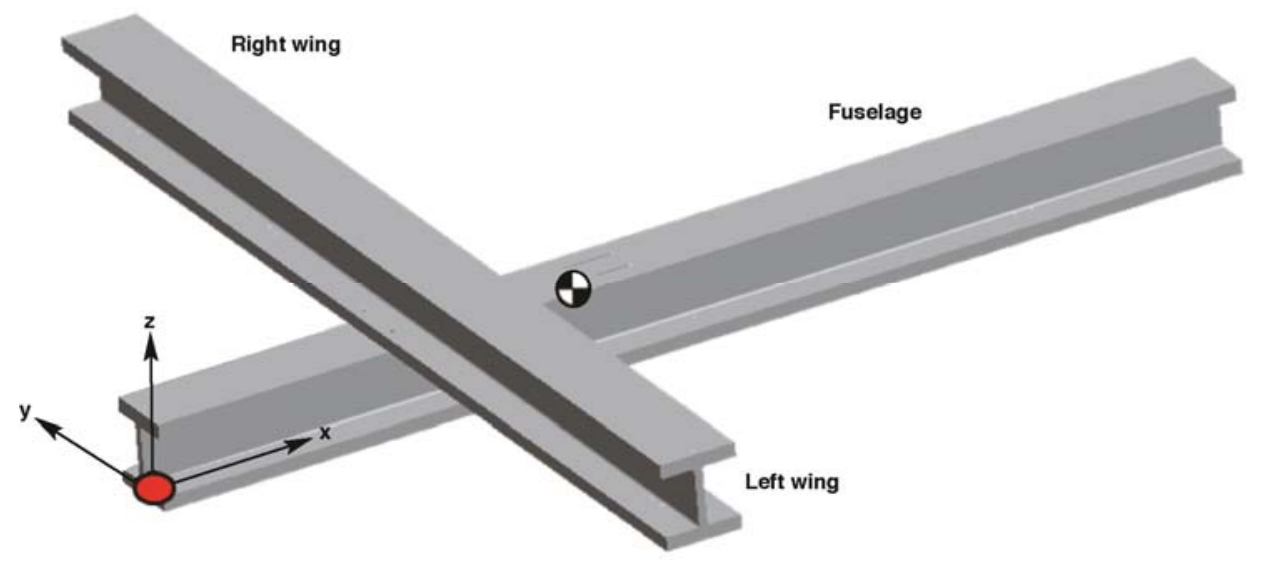

Figure 2. The CAD model showing the coordinate system for the iron bird.

\section{The Analytic Model}

Pro/ENGINEER ${ }^{\circledR}$ was used to analytically model the iron bird test article and obtain the mass properties. Care was taken to apply as many realistic details to the CAD model as possible including all holes and adding interface attachments. The simplicity of the iron bird test article design was to ensure the analytical CAD model could be treated as the truth model. Table 1 shows the analytic mass properties of the iron bird from the CAD model.

Table 1. The CAD model analytical mass properties of the iron bird.

\begin{tabular}{|c|c|c|c|c|c|c|c|c|c|}
\hline Mass, lb & $\mathrm{X}_{\mathrm{CG}}$, in & $\mathrm{Y}_{\mathrm{CG}}$, in & $\mathrm{Z}_{\mathrm{CG}}$, in & $\begin{array}{l}\text { Ixx, } \\
l^{*}{ }^{*} \text { in }^{2}\end{array}$ & Iyy, lb*in ${ }^{2}$ & $\begin{array}{l}\text { Izz, } \\
\mathrm{lb}^{*} \mathrm{in}^{2}\end{array}$ & $\begin{array}{l}\text { Ixy, } \\
l^{*}{ }^{*} \text { in }^{2}\end{array}$ & $\begin{array}{l}\text { Ixz, } \\
\left(\mathrm{lb}^{*} \mathrm{in}^{2}\right)\end{array}$ & $\begin{array}{c}\text { Iyz, } \\
1 \mathrm{~b} * \mathrm{in}^{2}\end{array}$ \\
\hline 17012 & 90.0 & 0.0 & 18.7 & $4.34 \times 10^{7}$ & $5.88 \times 10^{7}$ & $9.74 \times 10^{7}$ & 0.0 & $\begin{array}{l}-4.78 \\
\times 10^{6}\end{array}$ & 0.0 \\
\hline
\end{tabular}

\section{The Pendulum Swing Tests}

Weight and balance measurements in conjunction with pendulum swing tests have been the conventional experimental method for obtaining mass properties of aerospace vehicles for almost a century. This analytically straightforward method focuses on measuring weight, periods, and pendulum lengths. Many problems can develop, however, when trying to meet the requirements for a successful test. The stiffness and integrity of the lifting hardware must be certified for NASA or any other lifting operations. In addition, the pendulum test hardware must be nearly frictionless to ensure minimal damping for accurate pendulum period measurements.

The $X_{C G}$ and $Y_{C G}$ were measured using a balance of forces calculation. The $Z_{C G}$ was not experimentally verified due to the level of effort required to tilt the iron bird at multiple angles for $Z_{C G}$ calculation. The experimentally-measured weight, $\mathrm{X}_{\mathrm{CG}}$, and $\mathrm{Y}_{\mathrm{CG}}$ are shown in Table 2. Uncertainties were calculated using the law of propagation of uncertainty methodology.

Table 2. Experimental weight, $X_{\mathrm{CG}}$, and $\mathbf{Y}_{\mathrm{CG}}$ :

\begin{tabular}{|l|c|c|c|c|}
\cline { 2 - 5 } \multicolumn{1}{c|}{} & Measured & Analytic & Diff analytic, $\%$ & Uncertainty \\
\hline Mass, $\mathrm{lb}$ & 16973 & 17012 & 0.23 & $+/-104.4$ \\
\hline $\mathrm{X}_{\mathrm{CG}}$ in & 90 & 90 & 0.00 & $+/-0.08245$ \\
\hline $\mathrm{Y}_{\mathrm{CG}}$ in & -0.03 & 0 & $\mathrm{n} / \mathrm{a}$ & $+/-0.08161$ \\
\hline
\end{tabular}

Classical pendulum equations were used to determine the moments of inertia. The methodology and equations referenced multiple NACA papers. ${ }^{8,9,10,11,12,13}$ In order to obtain the moments of inertia of the iron bird, all tests also 
required swinging the fixture by itself in order to subtract out the fixture mass properties from the total combined iron bird and fixture assembly. The moments of inertia about the x-axis and y-axis used a compound pendulum setup and is calculated from Eq. (5), where terms with a subscript of "1" represent the combined test article and fixture; terms with a subscript of "2" represent the fixture only; and " $L$ " is the length from the pivot point to the CG of the respective subscripts.

$$
\mathrm{I}_{\mathrm{xx} \text { ETA }}=\left[\frac{\mathrm{w}_{1} \mathrm{~T}_{1}{ }^{2} \mathrm{~L}_{1}}{4 \pi^{2}}-\frac{\mathrm{w}_{1} \mathrm{~L}_{1}{ }^{2}}{\mathrm{~g}}\right]-\left[\frac{\mathrm{w}_{2} \mathrm{~T}_{2}{ }^{2} \mathrm{~L}_{2}}{4 \pi^{2}}-\frac{\mathrm{w}_{2} \mathrm{~L}_{2}{ }^{2}}{\mathrm{~g}}\right]
$$

The z-axis MOI uses a bifilar torsional pendulum setup and is calculated from Eq. (6). The "L" term is the suspended length from the pivot point.

$$
\mathrm{I}_{\mathrm{zz} \mathrm{ETA}}=\frac{\mathrm{T}_{1}{ }^{2} \mathrm{w}_{1} \mathrm{~A}^{2}}{16 \pi^{2} \mathrm{~L}}-\frac{\mathrm{T}_{2}{ }^{2} \mathrm{w}_{2} \mathrm{~A}^{2}}{16 \pi^{2} \mathrm{~L}}
$$

Figure 3 shows the iron bird test article undergoing Ixx pendulum testing; Fig. 4 shows the iron bird test article undergoing Izz pendulum testing.

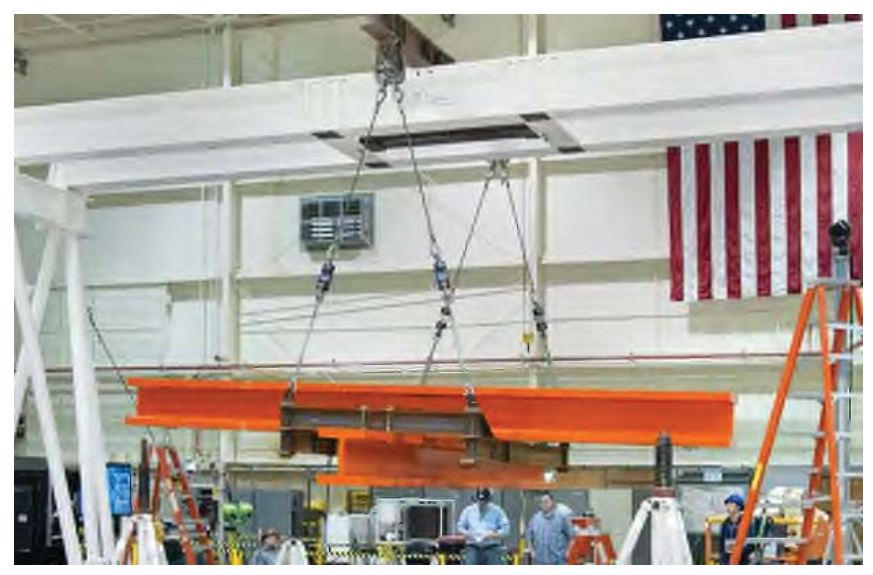

Figure 3. The iron bird undergoing $I_{x x}$ pendulum testing.

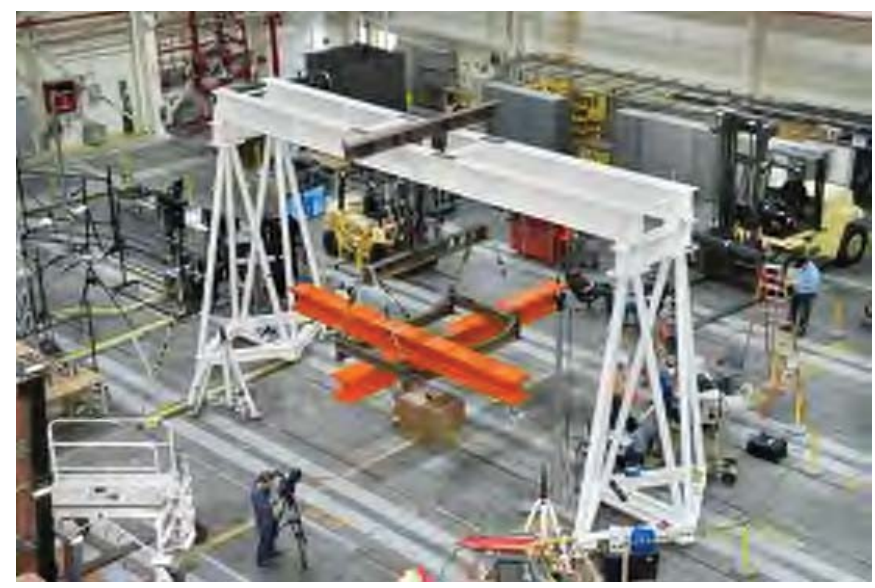

Figure 4. The iron bird undergoing $I_{z z}$ pendulum testing. 
Obtaining the product of inertia, $I_{x z}$, required the iron bird to rotate in the bifilar pendulum in a tilted pitch configuration. Due to limitations of the test setup, only a tilt of 5 deg was achievable, instead of the minimum 15 deg needed. This condition led to a large $\mathrm{I}_{\mathrm{xz}}$ error compared to the analytical predictions. The results of the iron bird MOI and POI are summarized in Table 3. The large $\mathrm{I}_{\mathrm{xz}}$ uncertainty comes from compounding uncertainties from $\mathrm{I}_{\mathrm{xx}}$ and $\mathrm{I}_{\mathrm{zz}}$ measurements. A small tilt angle exacerbates the uncertainty as well.

Table 3. Summary of iron bird pendulum MOI results.

\begin{tabular}{|l|c|c|c|c|}
\hline & $\begin{array}{c}\text { Measured MOI, } \\
\mathrm{lb}^{*} \mathrm{in}^{2}\end{array}$ & $\begin{array}{c}\text { Analytic MOI, } \\
\mathrm{lb}^{*} \text { in }^{2}\end{array}$ & Diff analytic, $\%$ & Uncertainty, \% \\
\hline $\mathrm{I}_{\mathrm{xx}}$ iron bird & $41,910,500$ & $43,425,000$ & -3 & 8 \\
\hline $\mathrm{I}_{\mathrm{yy}}$ iron bird & $61,277,050$ & $58,762,677$ & 4 & 10 \\
\hline $\mathrm{I}_{\mathrm{zz}}$ iron bird & $95,160,000$ & $97,413,170$ & -2 & 3.4 \\
\hline $\mathrm{I}_{\mathrm{xz}}$ iron bird & $-9,455,126$ & $-4,775,509$ & 98 & 242.7 \\
\hline
\end{tabular}

Several difficulties with the test setup and the data were encountered using the pendulum method. Weight exceeding safety close calls was an ever-present concern. Oscillations damped out more quickly than was expected and the frequency oscillation was not constant. Post-test analysis revealed that the main culprit for the observed frequency changes was the non-ideal design of the pendulum test hardware.

\section{Dynamic Inertia Measurement Testing}

The iron bird DIM testing was conducted at the NASA AFRC Flight Loads Laboratory (FLL) from September 16, 2013 through September 24, 2013. ATA Engineering, Inc. (San Diego, California) was contracted to assist with the iron bird DIM testing and to perform analysis of the data, in order to utilize their previous experience with the DIM method. ${ }^{14,15}$ The equipment required and test description required for the DIM method test is described below.

\section{A. Equipment}

The DIM method requires many of the same sensors (accelerometers, force transducers, and soft-support load cells) and equipment (shakers, soft-support system) that are needed to perform a GVT. In addition to the GVT equipment, a few specialized sensors, such as 6-DOF force sensors, 3-DOF force transducers, laser tracker, and seismic accelerometers, are required for DIM. The 6-DOF loads cells ensure all reaction forces and moments needed for the DIM calculation are measured. The seismic accelerometers have a higher sensitivity and lower noise floor which may be needed to accurately record low-amplitude responses. The DIM processing will evaluate and compare the need for the seismic accelerometers versus typical GVT accelerometers. A data acquisition system was used to acquire and record data from all the sensors installed during DIM testing. Each sensor location and orientation was measured with a laser tracker.

\section{Soft Support System}

The 60,000-lb Starr Soft Support (60K3S) system is a specialized piece of equipment that acts as both an aircraft jack and a nitrogen bladder soft-support system. The soft suspension system was used to support the iron bird in order to simulate free-free boundary conditions as accurately as possible. ${ }^{16}$

\section{3-DOF Load Cells: Soft Supports}

On each of the soft supports, a 3-DOF load cell (Interface 5200 series) (Interface, Inc., Scottsdale, Arizona) was used to monitor the $60 \mathrm{~K} 3 \mathrm{~S}$ side loads and ensure that load limits were not exceeded. This information was not used in the DIM calculation. These load cells are part of the standard instrumentation for using the soft supports for GVTs. The 3-DOF 60K3S load cells are shown in Fig. 5.

\section{6-DOF Force Sensors: Reaction}

Three 6-DOF force sensors were custom-made for the NASA AFRC researchers by PCB Piezotronics, Inc. (Depew, New York). These unique sensors are an assembly of three 3-DOF piezoelectric dynamic force sensors. The force sensors were placed between the iron bird and the soft-support system. A picture of the 6-DOF force sensor is shown in Fig. 5. 

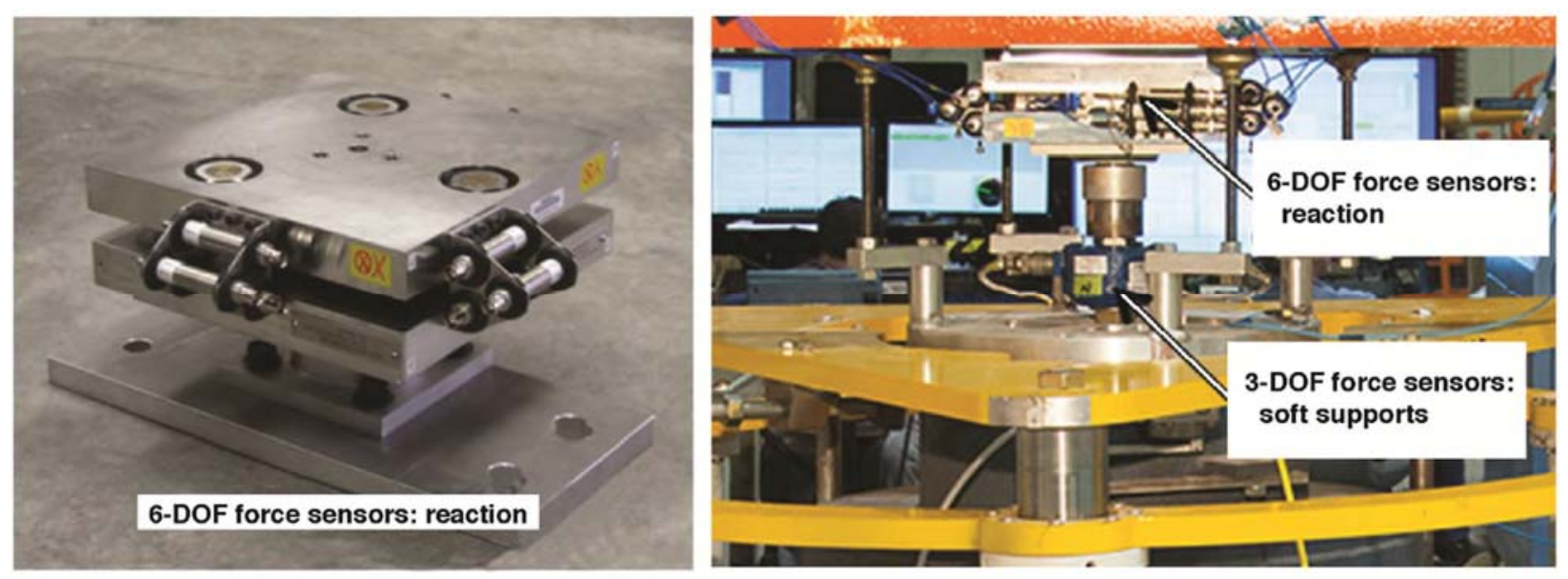

Figure 5. Left, the 6-DOF reaction force sensor; and right, the 3-DOF soft support load cell.

\section{Shakers: Excitation}

The DIM testing required up to two shakers for excitation during random and sine-sweep test runs. For all configurations, either one or two 110-pound MB Dynamics (Cleveland, Ohio) electrodynamic shakers were used to excite the structure.

\section{3-DOF Force Transducer: Excitation}

3-DOF excitation force sensor was used to measure the input force from the shaker. The axis of the force transducer in line with the shaker was the reference for the FRF measurements; the other two axes were treated as reaction forces. The transverse forces were typically only a few percent of the in-line force.

6. Accelerometers

Three sets of accelerometers were installed for the DIM test: seismic accelerometers, single-axis accelerometers, and triaxial accelerometers. Seismic accelerometers were used for their higher sensitivity and to evaluate the necessity to capture acceleration for more massive objects. Single-axis accelerometers are typically used for a modal GVT; they were also mounted in a triaxial configuration collocated with the seismic accelerometers. The purpose of this redundancy was to compare the DIM processing results between these two types of sensors and evaluate the adequacy of typical modal accelerometers as compared to the expensive seismic accelerometers required for DIM testing. The triaxial accelerometers were mounted on the wings, fuselage, and soft supports for modal information.

\section{B. Test Description}

A total of twelve different DIM analysis cases were conducted through the course of 54 test runs. These runs included check-out, single-shaker, multi-shaker, and quiescent runs.

During preliminary test runs, unexpected soft-support modes in the frequency range of 6 to $14 \mathrm{~Hz}$ were observed. Additional accelerometers were installed on the $60 \mathrm{~K} 3 \mathrm{~S}$ to characterize these modes. Based on the observed mode shapes, the lower portion of the soft support was constrained to the supporting frame before testing was resumed.

The added constraints to the $60 \mathrm{~K} 3 \mathrm{~S}$ increased the stiffness, and the $60 \mathrm{~K} 3 \mathrm{~S}$ modes moved from the frequency range of 6 to $14 \mathrm{~Hz}$ to the frequency range of 10 to $18 \mathrm{~Hz}$ to aid in the frequency separation necessary for the DIM calculation. The power spectrum mode indicator functions (PSMIFs), a summation of the squared-magnitude of the FRF, plotted in Fig. 6 show the effect of the added constraints with the original PSMIF (solid blue) compared to the modified PSMIF (dashed blue). The other PSMIF lines were taken at the start of each testing day to verify that the 60K 3 S modes were still beyond the $10 \mathrm{~Hz}$ range. 


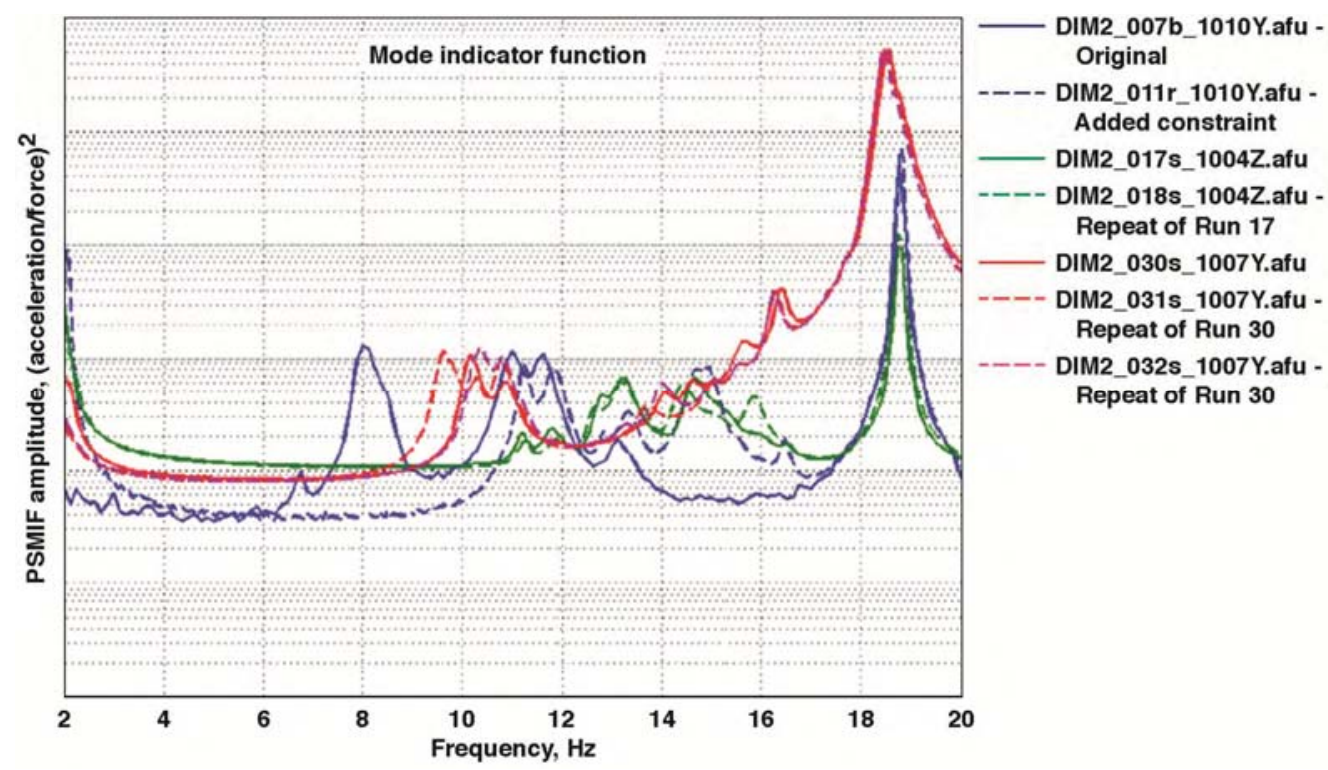

Figure 6. Power spectrum mode indicator functions showing the effect of added constraints on the $60 \mathrm{~K} 3 \mathrm{~S}$.

For reference, modes extracted from the multiple-shaker random run (run 43) are provided in Table 4. All six iron bird rigid body modes were extracted and were at less than $2 \mathrm{~Hz}$. The first set of $60 \mathrm{~K} 3 \mathrm{~S}$ modes were in the frequency range of 10 to $18 \mathrm{~Hz}$. The first flexible mode of the iron bird was at $18.7 \mathrm{~Hz}$.

Table 4. Modes extracted from the multiple-shaker random run of the iron bird.

\begin{tabular}{|l|c|c|l|}
\hline Mode & Frequency, Hz & $\begin{array}{c}\text { Damping, } \% \\
\text { critical }\end{array}$ & Description \\
\hline 1 & 0.72 & 8.52 & Rigid body pitch \\
\hline 2 & 0.98 & 6.32 & Rigid body roll \\
\hline 3 & 1.25 & 3.81 & Rigid body yaw \\
\hline 4 & 1.56 & 6.21 & Rigid body vertical \\
\hline 5 & 1.80 & 2.99 & Rigid body fore-aft \\
\hline 6 & 1.99 & 2.91 & Rigid body lateral \\
\hline 7 & 10.08 & 1.99 & Starboard $60 \mathrm{~K} 3 \mathrm{~S}$ canister $\mathrm{X}+/ \mathrm{Y}-$ \\
\hline 8 & 11.13 & 1.27 & Port 60K3S canister $\mathrm{X}+/ \mathrm{Y}-$ \\
\hline 9 & 11.47 & 1.46 & Starboard $60 \mathrm{~K} 3 \mathrm{~S}$ canister $\mathrm{X}+/ \mathrm{Y}+$ \\
\hline 10 & 12.41 & 0.98 & Aft 60K3S canister $\mathrm{RZ}$ \\
\hline 11 & 12.96 & 1.77 & Aft 60K3S canister $\mathrm{X}+/ \mathrm{Y}-$ \\
\hline 12 & 13.78 & 1.27 & Aft $60 \mathrm{~K} 3 \mathrm{~S}$ canister $\mathrm{X}+/ \mathrm{Y}+$ \\
\hline 13 & 13.79 & 1.52 & Starboard $60 \mathrm{~K} 3 \mathrm{~S} \mathrm{X}+\mathrm{Y}-$ \\
\hline 14 & 14.88 & 1.00 & Port 60K3S X+/Y+ \\
\hline 15 & 15.61 & 1.07 & Starboard $60 \mathrm{~K} 3 \mathrm{~S} \mathrm{X}+\mathrm{Y}+$ \\
\hline 16 & 16.37 & 0.72 & Port 60K3S lateral \\
\hline 17 & 18.23 & 2.03 & Aft 60K3S lateral \\
\hline 18 & 18.73 & 0.24 & Iron bird first flexible mode \\
\hline
\end{tabular}


Several parameters during the DIM testing were changed to evaluate and compare the results of the DIM calculations to determine which parameters worked well and which did not. Each DIM analysis case consisted of two or more test runs. Several types of shaker excitation were used for the DIM testing: single-shaker and multiple-shaker burst random, true random, and sine-sweep excitation. The shakers were also placed at various locations (nose, right wing, left wing, and tail) around the test article to determine the ideal excitation locations for the DIM calculation. The list of cases is shown in Table 5. Figure 7 shows the iron bird test article undergoing DIM testing on soft supports with two shakers for excitation.

Table 5. Dynamic Inertia Method analysis cases.

\begin{tabular}{|l|l|l|l|}
\hline $\begin{array}{l}\text { Analysis } \\
\text { case }\end{array}$ & $\begin{array}{l}\text { Shaker } \\
\text { configuration }\end{array}$ & Shaker excitation & Accelerometers \\
\hline 1 & Single & Random $(0$ to $100 \mathrm{~Hz})$ & Seismic \\
\hline 2 & Single & Random $(0$ to $12 \mathrm{~Hz})$ & Seismic \\
\hline 3 & Single & Sine sweep $(1$ to $20 \mathrm{~Hz})$ & Seismic \\
\hline 4 & Single & Random $(0$ to $100 \mathrm{~Hz})$ & GVT \\
\hline 5 & Single & Random $(0$ to $12 \mathrm{~Hz})$ & GVT \\
\hline 6 & Single & Sine sweep $(1$ to $20 \mathrm{~Hz})$ & GVT \\
\hline 7 & Double & Random $(0$ to $100 \mathrm{~Hz})$ & Seismic \\
\hline 8 & Double & Random $(0$ to $12 \mathrm{~Hz})$ & Seismic \\
\hline 9 & Double & Sine sweep $(1$ to $20 \mathrm{~Hz})$ & Seismic \\
\hline 10 & Double & Random $(0$ to $100 \mathrm{~Hz})$ & GVT \\
\hline 11 & Double & Random $(0$ to $12 \mathrm{~Hz})$ & GVT \\
\hline 12 & Double & Sine sweep $(1$ to $20 \mathrm{~Hz})$ & GVT \\
\hline
\end{tabular}

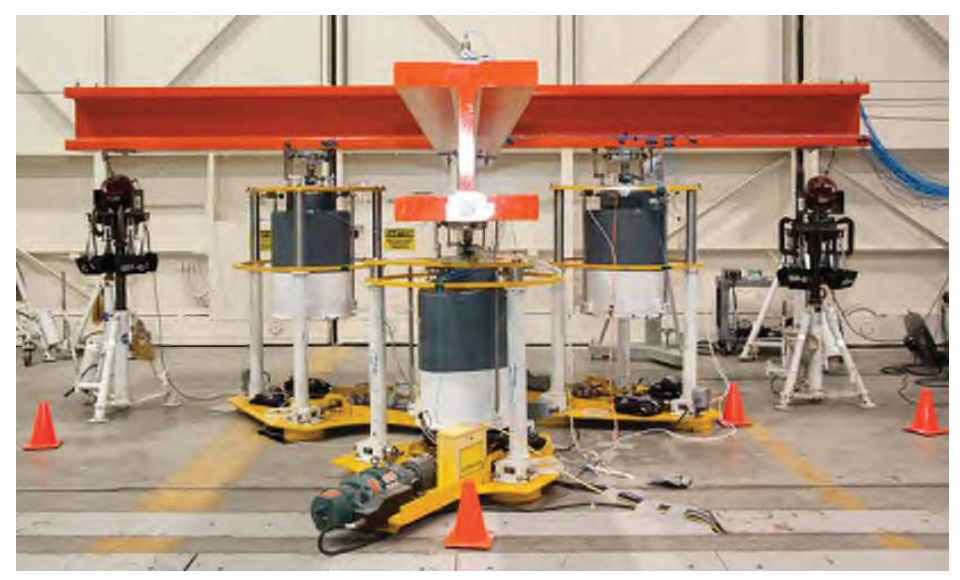

Figure 7. The iron bird undergoing DIM testing on soft supports.

\section{Results}

Post processing tools were used to extract the FRFs from the test data. The FRFs were analyzed using the ATA Engineering IMAT+SignalTM analysis software. "IMAT" stands for "Interface between MATLAB ${ }^{\mathrm{TM}}$, Analysis, and Test."

1. DIM Analysis

The PSMIF for the two-shaker random 0- to $100-\mathrm{Hz}$ excitation analysis case is shown in Fig. 8. Two PSMIFs are shown: the blue function is the PSMIF for only the DOFs on the iron bird; the green function is the PSMIF for all DOFs, which also includes the DOFs on the $60 \mathrm{~K} 3 \mathrm{~S}$. While the soft-suspension modes in the frequency range of 
10 to $17 \mathrm{~Hz}$ are clearly seen in the PSMIF of all DOFs, they are localized modes of the soft supports and have little response in the iron bird DOFs. The rigid body modes of the iron bird on the soft supports are at $2 \mathrm{~Hz}$ and below, and the flexible modes are above $18 \mathrm{~Hz}$, which is sufficient separation for estimating the inertia properties in this frequency range. The existence of the soft-suspension modes starting at $10 \mathrm{~Hz}$ and becoming prominent at $12 \mathrm{~Hz}$, however, limited the frequency range over which the DIM calculations were performed. Two frequency ranges were analyzed and evaluated to determine the effects of frequency range on DIM analysis results.

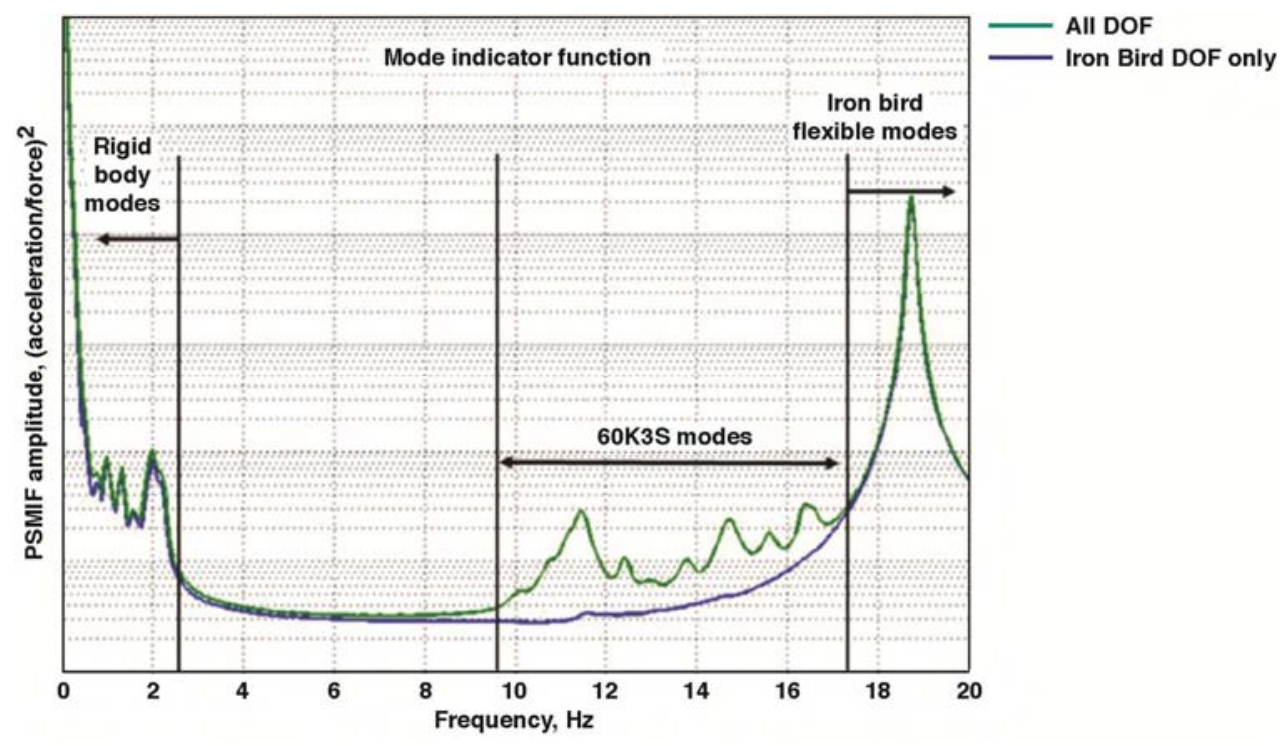

Figure 8. Power spectral mode indicator function for DIM analysis case 1.

\section{Comparison of Seismic and Ground Vibration Test Accelerometers}

One objective of the DIM test was to determine whether typical GVT accelerometers would be sufficient for accurate DIM analysis or if higher sensitivity seismic accelerometers would be required. A set of DIM analysis cases were performed using both the seismic accelerometers (DIM analysis case 1) and typical modal test GVT accelerometers (DIM analysis case 4). The normalized error functions were calculated as part of the DIM analysis cases and were used to compare the seismic and the GVT accelerometer results. The normalized error functions calculated using the seismic accelerometers for DIM analysis case 1 are shown in Fig. 9.

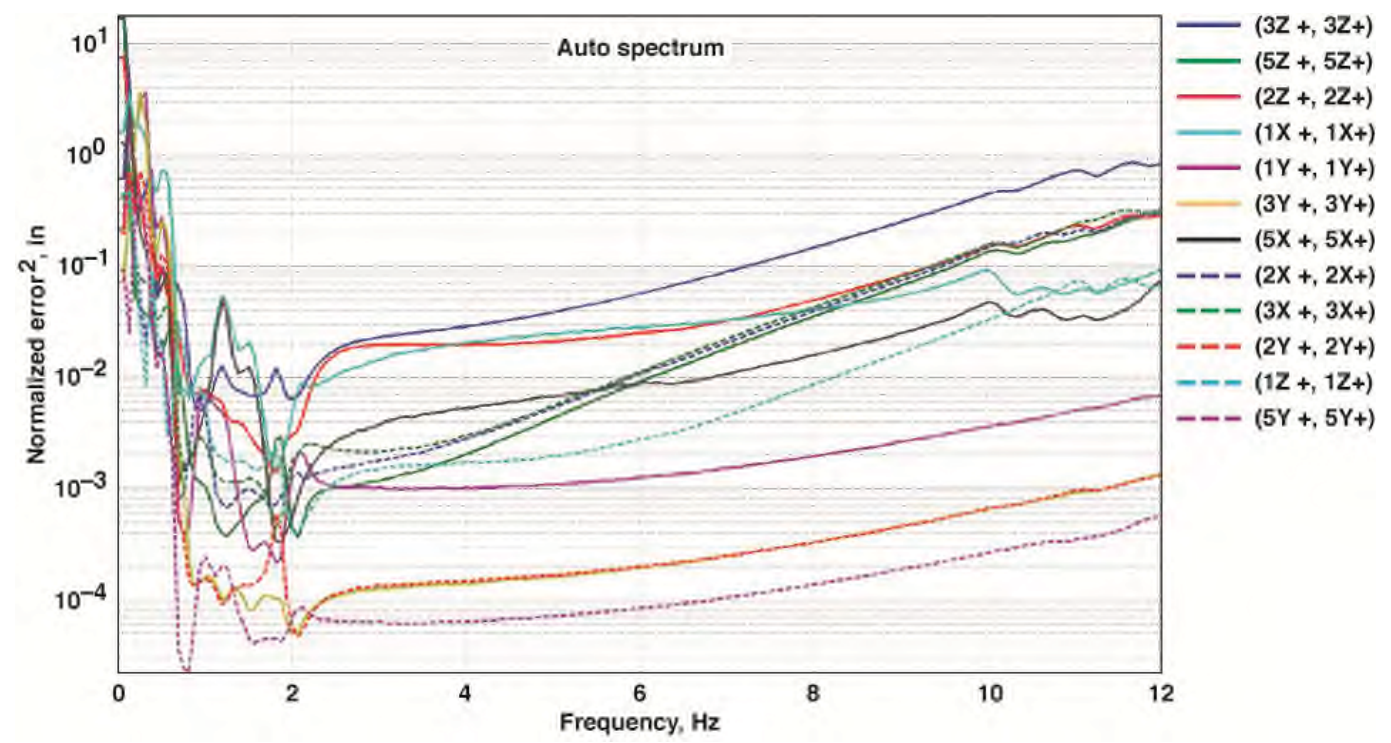

Figure 9. Normalized error function using the seismic accelerometers for DIM analysis case 1. 
No DOFs were consistently and significantly large enough for all test cases to warrant removing them from the mass properties calculations. The normalized error functions calculated using the GVT accelerometers for DIM analysis case 4 are shown in Fig. 10. The test runs included in DIM analysis case 4 are the same as those used for DIM analysis case 1, but used the GVT accelerometers instead of the seismic accelerometers. While the error has more variance due to the higher noise floor of the GVT accelerometers, the magnitude of the error is approximately the same as that seen with use of the seismic accelerometers. As expected, the overall mass properties results from the seismic accelerometers were consistently more in agreement with analytical predictions due to the lower noise floor. The seismic accelerometers were thought to be required because of their higher sensitivity: the higher sensitivity creates a lower noise floor, which enables acquisition of cleaner data. The cleaner data lessen the variation in the results as compared to the data obtained using GVT accelerometers.

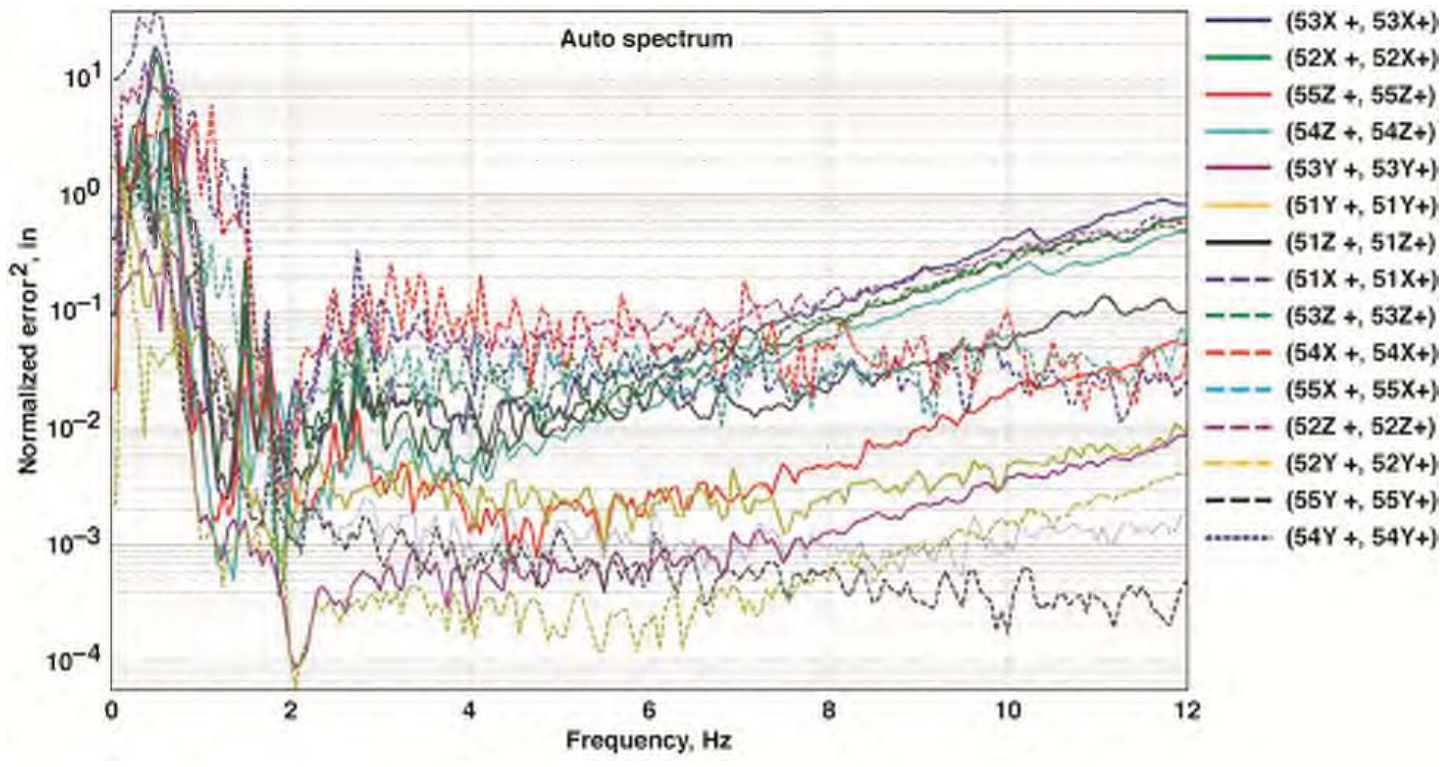

Figure 10. Normalized error function using the GVT accelerometers for DIM analysis case 4.

\section{Dynamic Inertia Measurement Results}

The computed mass, MOI, POI, and CG values are plotted as a function of frequency for DIM analysis case 1 in Fig. 11 for a 2- to 12-Hz DIM analysis. The mass, XCG and ZCG, three MOIs, and Ixz functions are relatively flat from $2 \mathrm{~Hz}$ to $12 \mathrm{~Hz}$. The YCG, Ixy, and Iyz functions exhibit greater fluctuations, but since these values are nominally zero and the estimated values are very small compared to the other CG and POI values, these fluctuations are to be expected. 


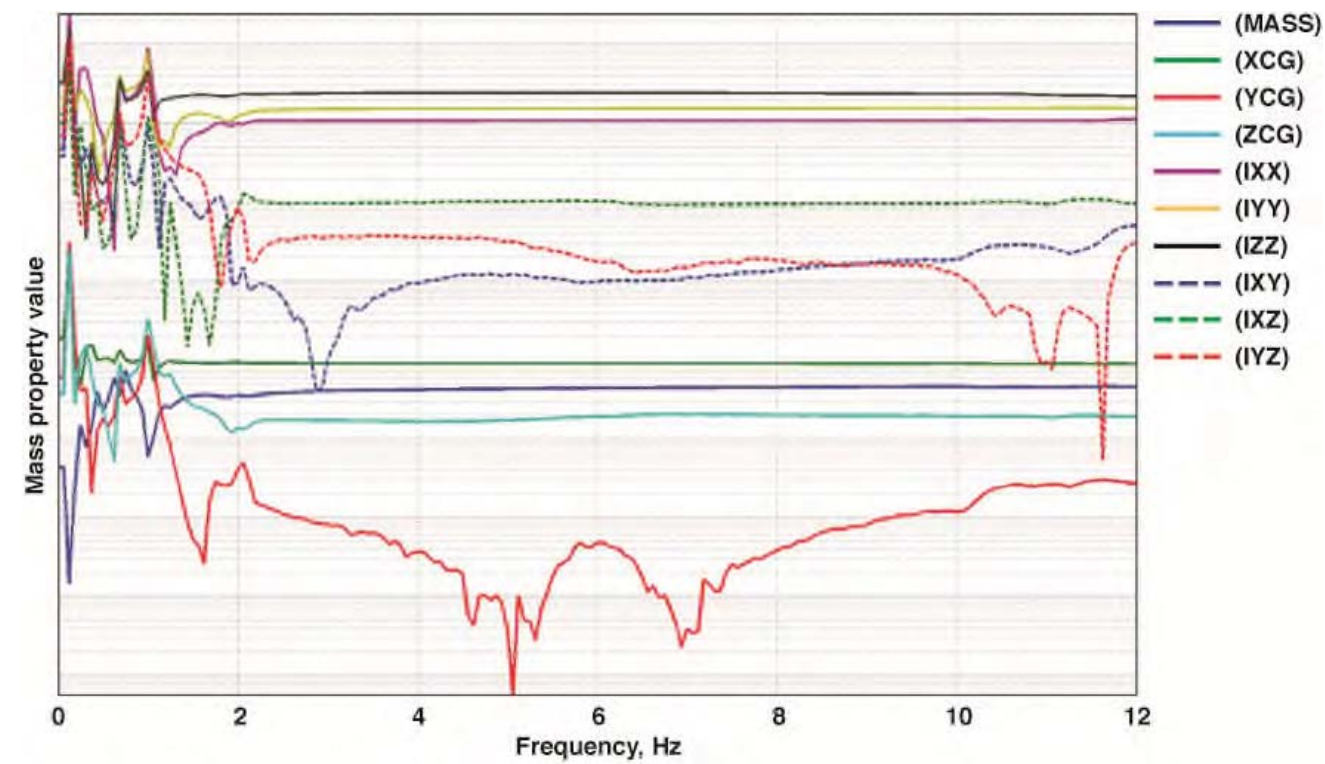

Figure 11. Computed mass properties for DIM analysis case 1.

The mass property functions were compared for all DIM analysis cases to determine the frequency band within which to compute average values. Plots of the mass, MOIs, and non-zero CG locations and POIs for all DIM analysis cases are provided in Figs. 12 through 18. An examination of the functions shows that the 2- to 12-Hz frequency band was fairly flat for all non-zero properties. A second smaller frequency band of 8 to $10 \mathrm{~Hz}$ was also used for DIM processing, because this band seemed to be the most consistent region over all of the analysis cases. In general, this smaller frequency range produced slightly larger mass properties results that were slightly higher than the results produced by the DIM analysis of the $2-$ to $12-\mathrm{Hz}$ band.

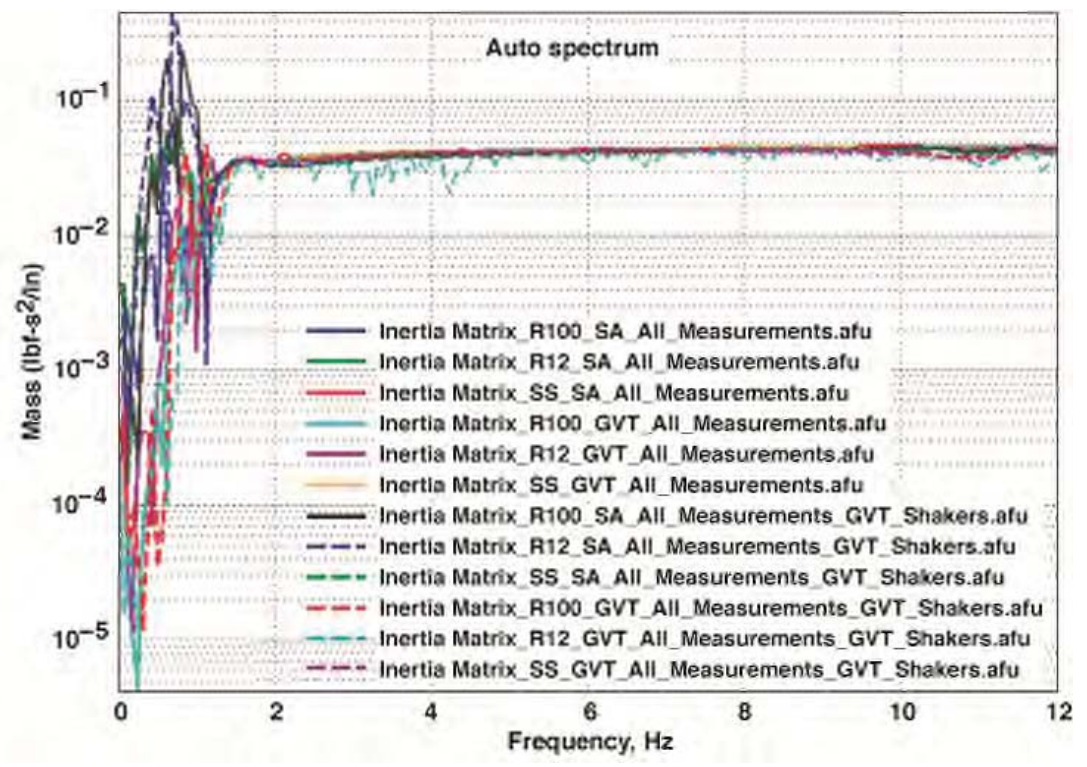

Figure 12. Computed mass function for all DIM analysis cases. 


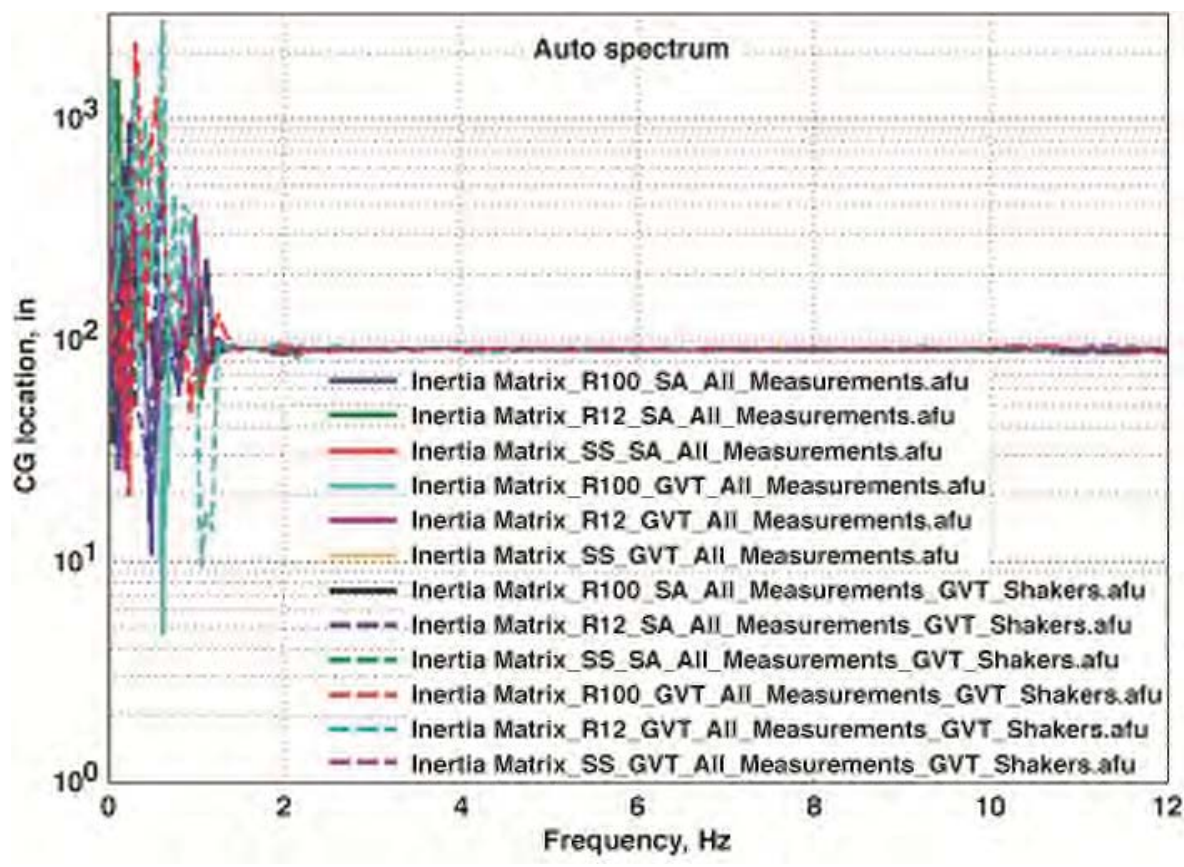

Figure 13. Computed $X_{C G}$ for all DIM analysis cases.

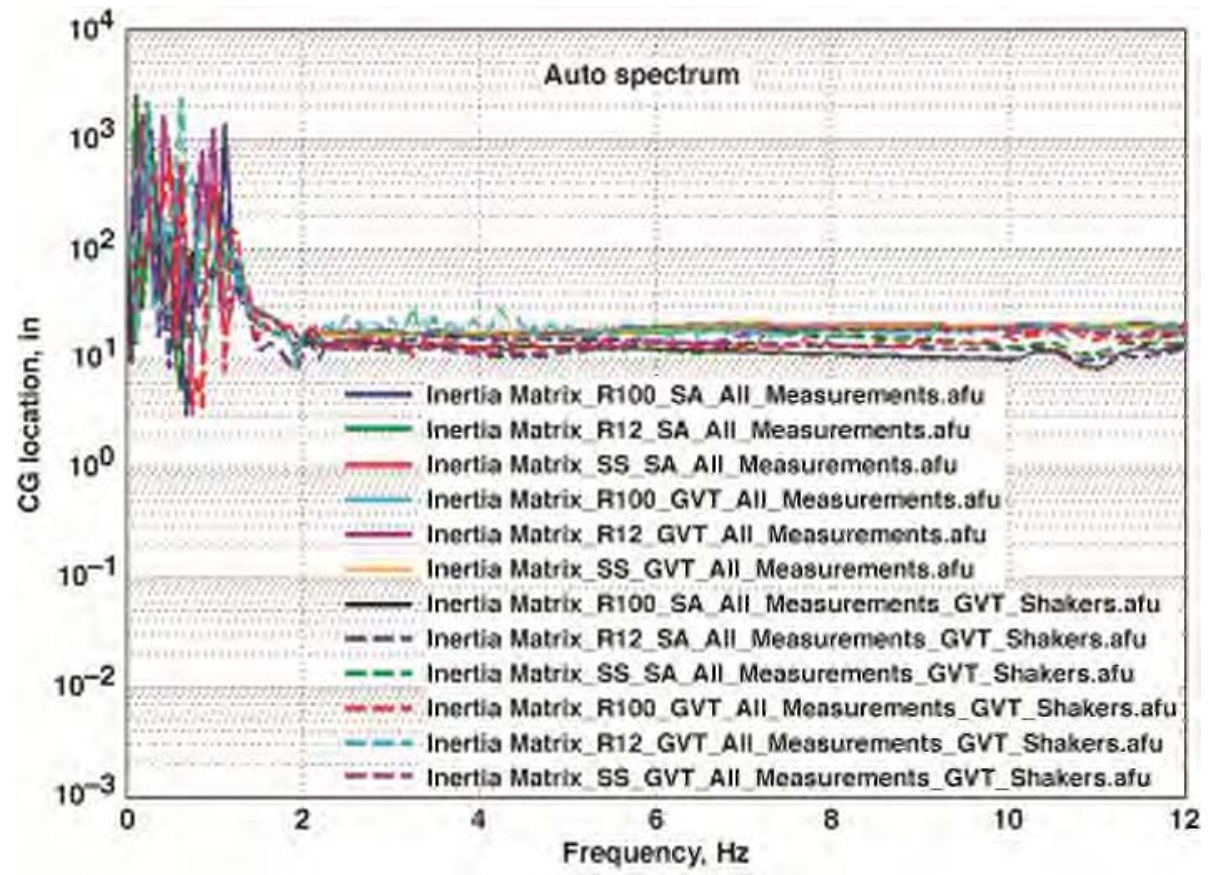

Figure 14. Computed $\mathrm{Z}_{\mathrm{CG}}$ functions for all DIM analysis cases. 


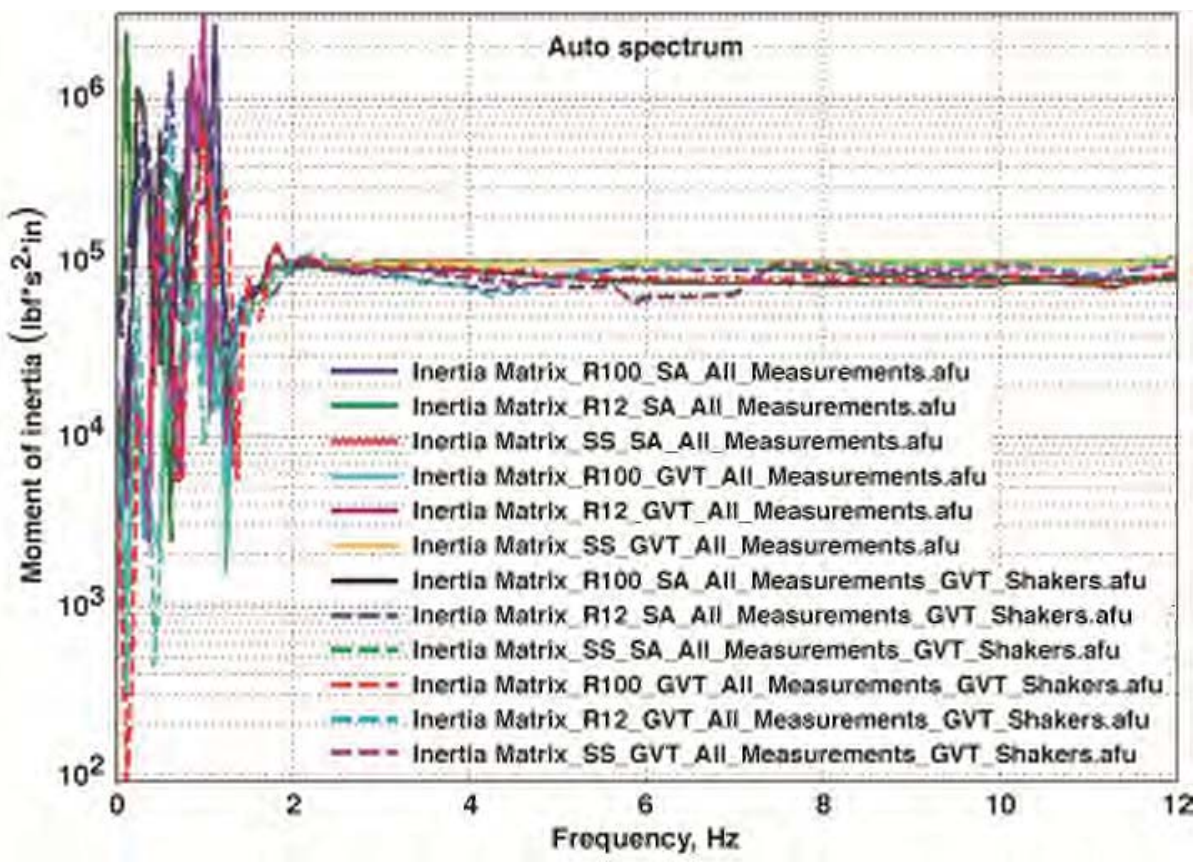

Figure 15. Computed $I_{x x}$ functions for all DIM analysis cases.

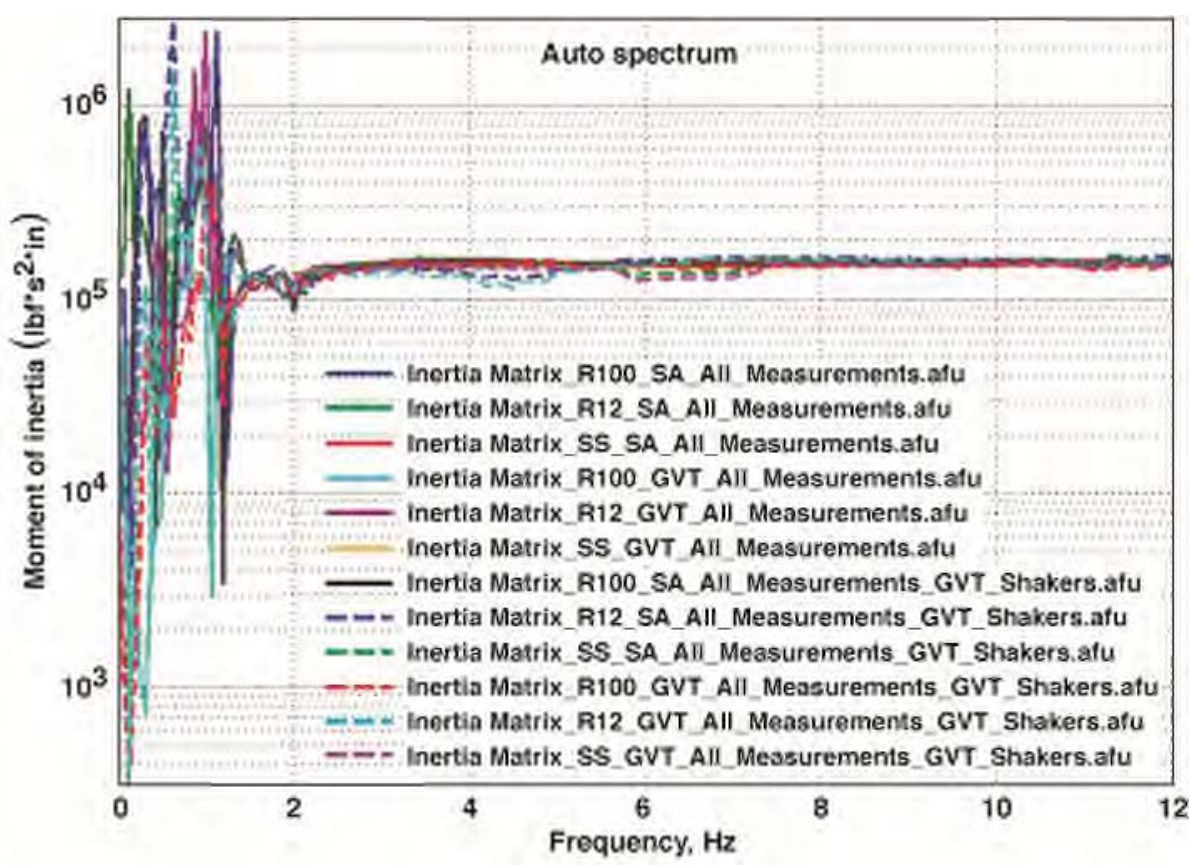

Figure 16. Computed $I_{y y}$ functions for all DIM analysis cases. 


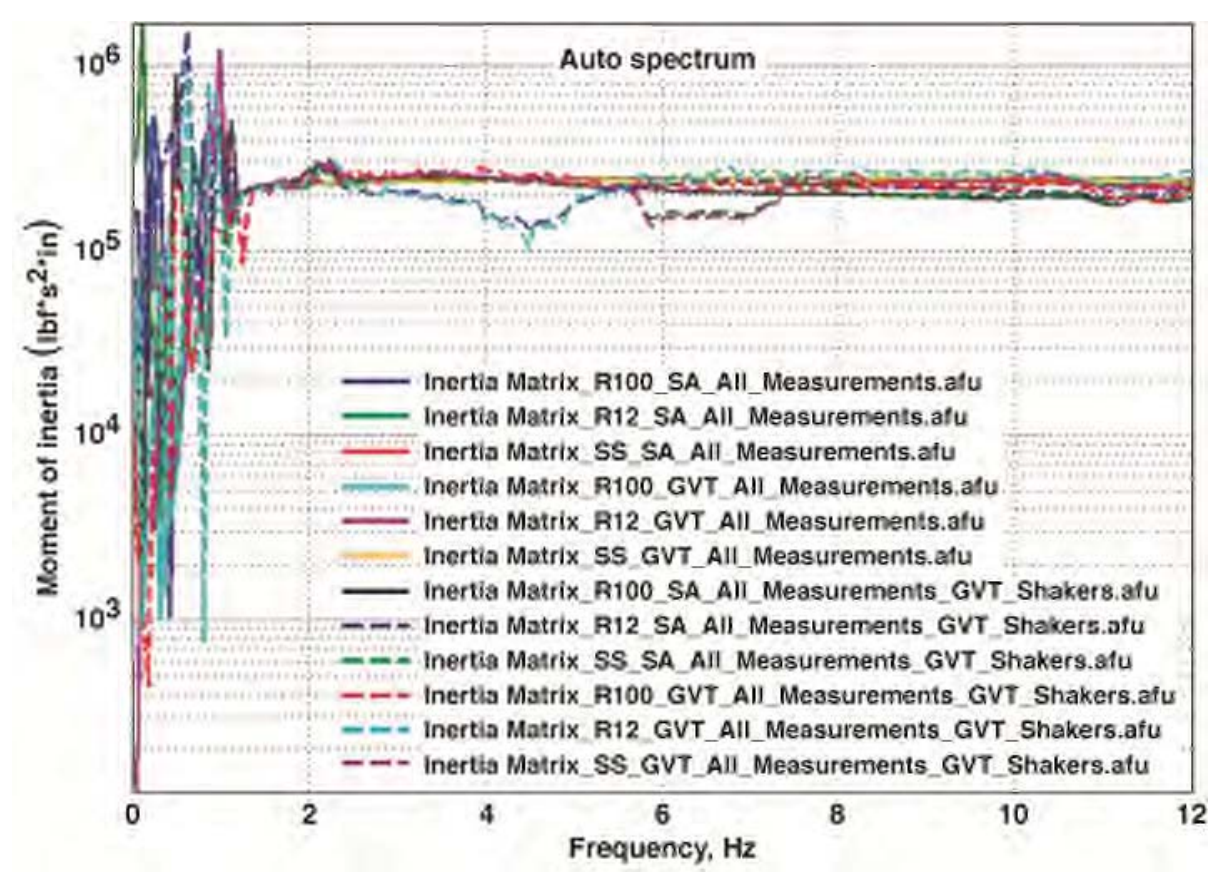

Figure 17. Computed $I_{z z}$ functions for all DIM analysis cases.

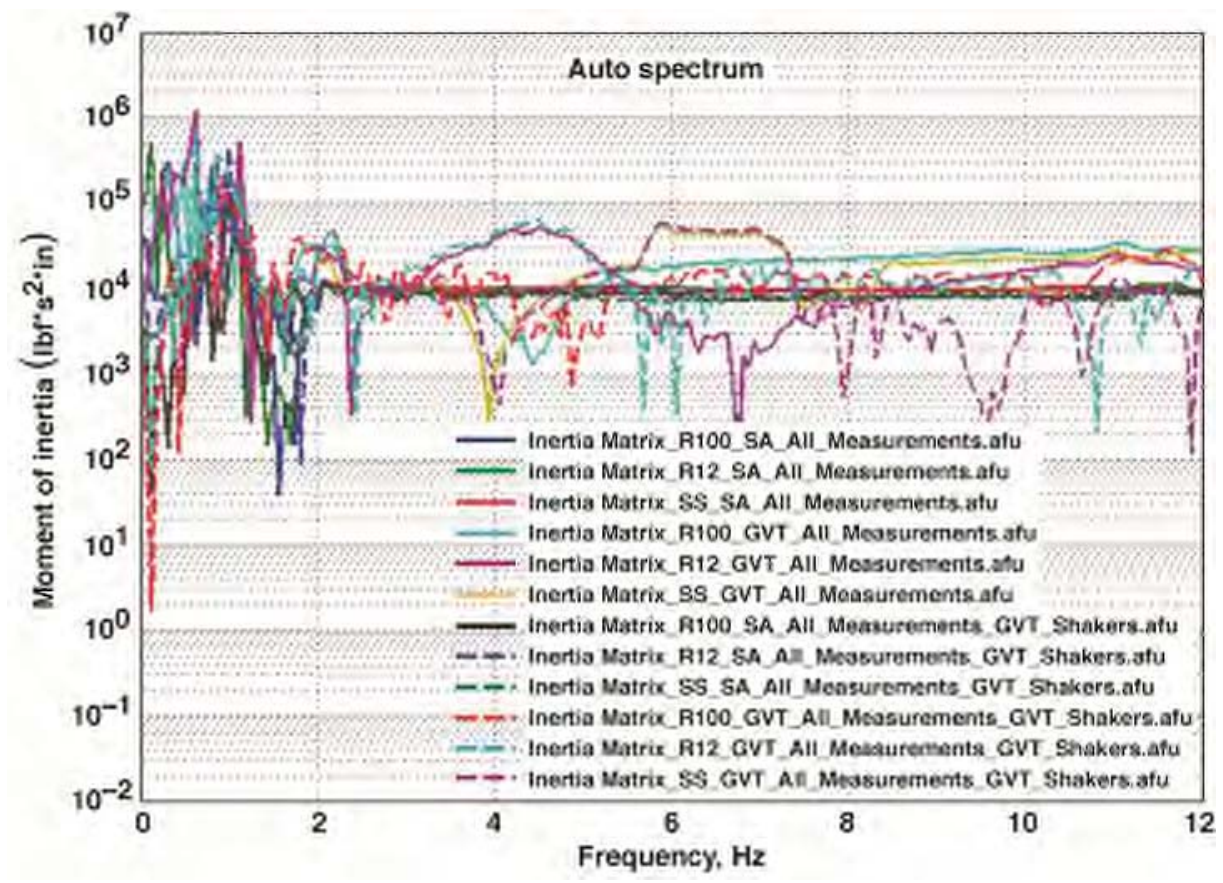

Figure 18. Computed $I_{x z}$ POI functions for all DIM analysis cases.

Tables 6-9 summarize the DIM analysis results. Note that the units for moments of inertia have been converted from $\mathrm{lbf}^{*} \mathrm{~s}^{2 *}$ in to $\mathrm{lbm} * \mathrm{in}^{2}$. Several parameters of the DIM analyses were varied during testing to investigate which produce the more accurate results. The 3-DOF force transducer provided a measurement for the excitation force in all three translational directions, which included the off-axis components of the input force. In the results presented above for the DIM analysis cases, the off-axis forces measured by the 3-DOF excitation force transducer were treated as additional reaction forces in the inertia calculations. For the two-shaker configurations, however, one of the inputs 
was measured with a single-axis force transducer because only one 3-DOF force transducer was available. To evaluate their effect on the computed mass properties, two DIM analysis cases were processed excluding the off-axis reaction forces. The two DIM analysis cases studied were the 0 - to $100-\mathrm{Hz}$ random excitation with seismic accelerometers for a single shaker (analysis case 1) and for two shakers (analysis case 7). The mass properties calculations for both cases are across the smaller frequency range of 8 to $10 \mathrm{~Hz}$. The results for the two DIM analysis cases with and without the off-axis forces are listed in Table 6. For both DIM analysis cases, the computed mass was less when not using the off-axis forces. For DIM analysis case 7, however, in which only one shaker had measured off-axis force, the MOIs increased slightly and were closer to DIM analysis case 1. Further study is recommended of the effects of the off-axis forces.

Table 6. Comparison of mass properties using DIM with and without off-axis forces.

\begin{tabular}{|c|c|c|c|c|c|c|c|c|c|c|c|c|c|c|c|c|c|}
\hline \multirow[b]{2}{*}{$\begin{array}{l}\text { Analysis } \\
\text { case }\end{array}$} & \multicolumn{17}{|c|}{8 - to $10-\mathrm{Hz}$ frequency range } \\
\hline & $\begin{array}{c}\text { MASS, } \\
\mathrm{lbm}\end{array}$ & $\begin{array}{c}\text { Mass, } \\
\% \text { error }\end{array}$ & $\begin{array}{c}\mathrm{X}_{\mathrm{CG}}, \\
\text { in }\end{array}$ & \begin{tabular}{|c|}
$\mathrm{X}_{\mathrm{CG}}$, \\
\% error \\
\end{tabular} & \begin{tabular}{|c}
$Y_{\mathrm{CG}}$ \\
in
\end{tabular} & \begin{tabular}{|c|}
$Z_{\mathrm{CG}}$ \\
in
\end{tabular} & $\begin{array}{c}Z_{\mathrm{CG}}, \\
\% \text { error }\end{array}$ & $\begin{array}{c}\mathrm{Ixx} \\
\mathrm{lbm}-\mathrm{in}^{2} \\
\end{array}$ & $\begin{array}{c}\text { Ixx, } \\
\% \text { error } \\
\end{array}$ & $\begin{array}{c}\mathrm{I}_{\mathrm{YY}}, \\
\mathrm{lbm}-\mathrm{in}^{2} \\
\end{array}$ & $\begin{array}{c}\text { IYY, } \\
\% \text { error } \\
\end{array}$ & $\begin{array}{c}\text { Izz, } \\
\mathrm{lbm}-\mathrm{in}^{2}\end{array}$ & \begin{tabular}{|c|} 
Izz, \\
$\%$ error \\
\end{tabular} & $\begin{array}{c}\mathrm{IXY}, \\
\mathrm{lbm}-\mathrm{in}^{2} \\
\end{array}$ & $\begin{array}{c}\text { Ixz, } \\
\text { lbm-in } \\
\end{array}$ & \begin{tabular}{|c|}
$\begin{array}{c}\mathrm{IXZ} \\
\% \text { error }\end{array}$ \\
\end{tabular} & $\begin{array}{c}\text { IYZ, } \\
\text { lbm-in }\end{array}$ \\
\hline & & & & & & & & $\mathrm{x} 10^{7}$ & & $\times 10^{7}$ & & $\mathrm{x} 10^{7}$ & & $\times 10^{5}$ & $\times 10^{5}$ & & $\mathrm{x} 10^{5}$ \\
\hline 1 & 17,596 & 3. $4 \%$ & 89.5 & $-0.6 \%$ & $-0.7 \mid 1$ & 19.1 & $2.0 \%$ & 4. 22 & $-2.7 \%$ & 6. 02 & 2. $3 \%$ & 9.21 & $-5.5 \%$ & -0.59 & -3.78 & $-21.0 \%$ & 0.53 \\
\hline 1 (no off-axis force) & 16,809 & $-1.2 \%$ & 89.7 & $-0.3 \%$ & -0.2 & 18.2 & $-2.7 \%$ & 4. 20 & $-3.3 \%$ & 5.97 & $1.5 \%$ & 9.22 & $-5.3 \%$ & -0.40 & -3.84 & $-19.8 \%$ & 0.51 \\
\hline 7 & 16,684 & $-1.9 \%$ & 89.4 & $-0.7 \%$ & 2.9 & 10.2 & $-45.3 \%$ & 3. 04 & $-30.0 \%$ & 5.83 & $-0.8 \%$ & 7.60 & $-22.0 \%$ & -3.91 & 9.70 & $-302.8 \%$ & -4.33 \\
\hline 7 (no off-axis force) & 15,904 & $-6.5 \%$ & 89.9 & $-0.1 \%$ & $|1.7| 1$ & $|12.6|$. & $-32.5 \%$ & 3.40 & $-21.7 \%$ & 5.96 & $1.4 \%$ & 8.48 & $-12.9 \%$ & -1.60 & 4.74 & $-199.2 \%$ & -0.02 \\
\hline
\end{tabular}

Table 7 summarizes the mass properties calculation across the $2-$ to $12-\mathrm{Hz}$ frequency range for all DIM analysis cases. These cases are calculated using the off-axis forces measured by the 3-DOF force transducer.

Table 7. Summary of mass properties using DIM for the 2- to $12-\mathrm{Hz}$ frequency range.

\begin{tabular}{|c|c|c|c|c|c|c|c|c|c|c|c|c|c|c|c|c|c|}
\hline \multirow[b]{2}{*}{$\begin{array}{l}\text { Analysis } \\
\text { case }\end{array}$} & \multicolumn{17}{|c|}{ 2- to $12-\mathrm{Hz}$ frequency range } \\
\hline & $\begin{array}{c}\text { MASS, } \\
\mathrm{lbm}\end{array}$ & $\begin{array}{l}\text { Mass, } \\
\% \text { error }\end{array}$ & $\begin{array}{c}\mathrm{X}_{\mathrm{CG}} \\
\text { in } \\
\end{array}$ & $\begin{array}{c}\mathrm{X}_{\mathrm{CG}}, \\
\% \text { error }\end{array}$ & $\begin{array}{c}Y_{\mathrm{CG}} \\
\text { in } \\
\end{array}$ & \begin{tabular}{|c|}
$Z_{\mathrm{CG}}$ \\
in \\
\end{tabular} & $\begin{array}{c}\mathrm{Z}_{\mathrm{CG}}, \\
\% \text { error }\end{array}$ & $\begin{array}{c}\text { Ixx, } \\
\text { lbm-in }{ }^{2}\end{array}$ & \begin{tabular}{|c|} 
Ixx, \\
$\%$ error \\
\end{tabular} & $\begin{array}{c}\text { IYY, } \\
\mathrm{lbm}-\mathrm{in}^{2} \\
\end{array}$ & $\begin{array}{c}\text { IYY, } \\
\% \text { error }\end{array}$ & $\begin{array}{c}\text { Izz, } \\
\text { lbm-in }\end{array}$ & $\begin{array}{c}\text { Izz, } \\
\text { \% error } \\
\end{array}$ & $\begin{array}{c}\mathrm{IXY}, \\
\mathrm{lbm}-\mathrm{in}^{2}\end{array}$ & $\begin{array}{c}\text { Ixz, } \\
\text { lbm-in }\end{array}$ & $\begin{array}{c}\text { Ixz, } \\
\% \text { error }\end{array}$ & $\begin{array}{c}\text { Iyz, } \\
\text { lbm-in } \\
\end{array}$ \\
\hline & & & & & & & & $\times 10^{7}$ & & $\mathrm{x} 10^{7}$ & & $\mathrm{x} 10^{7}$ & & $\mathrm{x} 10^{6}$ & $\mathrm{x} 10^{6}$ & & $\mathrm{x} 10^{6}$ \\
\hline 1 & 16,805 & $-1.2 \%$ & 89.7 & $-0.3 \%$ & -0.2 & 18.2 & $-2.6 \%$ & 4. 20 & $-3.3 \%$ & 5.97 & $1.4 \%$ & 9.23 & $-5.3 \%$ & -0.41 & -3.83 & $-19.8 \%$ & 0.64 \\
\hline 2 & 16,824 & $-1.1 \%$ & 89.7 & $-0.3 \%$ & -0.4 & 18.6 & $-0.7 \%$ & 4. 20 & $-3.2 \%$ & 5. 94 & $1.0 \%$ & 9.23 & $-5.3 \%$ & -0.53 & -3.81 & $-20.3 \%$ & 0.78 \\
\hline 3 & 16,756 & $-1.5 \%$ & 89.7 & $-0.4 \%$ & -0.5 & 18.5 & $-1.0 \%$ & 4. 20 & $-3.3 \%$ & 5.94 & 1. $0 \%$ & 9.23 & $-5.3 \%$ & -0.53 & -3.74 & $-21.9 \%$ & 0.94 \\
\hline 4 & 16,477 & $-3.1 \%$ & 90.5 & $0.6 \%$ & 1.1 & 17.5 & $-6.2 \%$ & 4. 17 & $-3.9 \%$ & 5.70 & $-3.1 \%$ & 9.41 & $-3.4 \%$ & -0.31 & -3.25 & $-32.1 \%$ & -0.94 \\
\hline 5 & 16,586 & $-2.5 \%$ & 90.5 & $0.5 \%$ & 1.0 & 18.1 & $-3.4 \%$ & 4. 17 & $-3.9 \%$ & 5.68 & $-3.3 \%$ & 9.41 & $-3.4 \%$ & -0.39 & -3.22 & $-32.7 \%$ & -0.84 \\
\hline 6 & 16,555 & $-2.7 \%$ & 90.5 & $0.5 \%$ & 0.9 & 18.0 & $-3.7 \%$ & 4. 17 & $-3.9 \%$ & 5.69 & $-3.2 \%$ & 9.40 & $-3.5 \%$ & -0.38 & -3.16 & $-33.8 \%$ & -0.71 \\
\hline 7 & 15,893 & $-6.6 \%$ & 89.7 & $-0.3 \%$ & 2.5 & 11.7 & $-37.7 \%$ & 3.29 & $-24.3 \%$ & 5.88 & $-0.1 \%$ & 8.30 & $-14.8 \%$ & -2.19 & 5.57 & $-216.6 \%$ & -1.02 \\
\hline 8 & 16,129 & $-5.2 \%$ & 89.4 & $-0.7 \%$ & 2.6 & 13.2 & $-29.4 \%$ & 3. 49 & $-19.6 \%$ & 5.90 & $0.3 \%$ & 8.10 & $-16.8 \%$ & -2.37 & 5.42 & $-213.4 \%$ & -1.43 \\
\hline 9 & 15,695 & $-7.7 \%$ & 90.2 & $0.2 \%$ & 1.8 & 12.9 & $-30.9 \%$ & 3.28 & $-24.4 \%$ & 5.90 & $0.4 \%$ & 8.16 & $-16.2 \%$ & -2.64 & 6.18 & $-229.2 \%$ & -1.88 \\
\hline 10 & 16,012 & $-5.9 \%$ & 90.5 & $0.6 \%$ & 2.2 & 13.9 & $-25.6 \%$ & 3.45 & $-20.5 \%$ & 5.65 & $-3.8 \%$ & 8.95 & $-8.1 \%$ & -1.44 & 2. 46 & $-151.4 \%$ & -1.66 \\
\hline 11 & 14,466 & $-15.0 \%$ & 90.4 & $0.5 \%$ & 1.5 & 18.2 & $-2.4 \%$ & 3.76 & $-13.3 \%$ & 5.69 & $-3.2 \%$ & 9.00 & $-7.6 \%$ & -1.03 & 0.85 & $-117.8 \%$ & -1.06 \\
\hline 12 & 15,754 & $-7.4 \%$ & 90.9 & $1.0 \%$ & 1.7 & 15.2 & $-18.6 \%$ & 3.45 & $-20.5 \%$ & 5.60 & $-4.8 \%$ & 8.73 & $-10.4 \%$ & -1.92 & 2. 94 & $-161.5 \%$ & -2.85 \\
\hline
\end{tabular}

Table 8 summarizes the mass properties calculation across the smaller 8 - to $10-\mathrm{Hz}$ frequency range for all DIM analysis cases. These cases are also calculated using the off-axis forces measured by the 3-DOF force transducer. 
Table 8. Summary of mass properties using DIM for the 8- to 10-Hz frequency range.

\begin{tabular}{|c|c|c|c|c|c|c|c|c|c|c|c|c|c|c|c|c|c|}
\hline \multirow[b]{2}{*}{$\begin{array}{l}\text { Analysis } \\
\text { case }\end{array}$} & \multicolumn{17}{|c|}{ 8-10 Hz Frequency Range } \\
\hline & $\begin{array}{c}\text { MASS, } \\
\text { lbm }\end{array}$ & $\begin{array}{l}\text { Mass, } \\
\text { \% error }\end{array}$ & $\begin{array}{c}\mathrm{X}_{\mathrm{CG}} \\
\text { in }\end{array}$ & $\begin{array}{c}\mathrm{X}_{\mathrm{CG}}, \\
\% \text { error }\end{array}$ & $\begin{array}{c}Y_{\mathrm{CG}}, \\
\text { in }\end{array}$ & $\begin{array}{c}Z_{\mathrm{CG}} \\
\text { in }\end{array}$ & $\begin{array}{c}Z_{\mathrm{CG}}, \\
\% \text { error }\end{array}$ & $\begin{array}{c}\text { Ixx, } \\
\text { lbm-in }{ }^{2}\end{array}$ & $\begin{array}{c}\text { IXx, } \\
\% \text { error }\end{array}$ & $\begin{array}{c}\mathrm{I}_{\mathrm{YY}}, \\
\mathrm{lbm}-\mathrm{in}^{2} \\
\end{array}$ & $\begin{array}{c}\text { IYY, } \\
\% \text { error }\end{array}$ & $\begin{array}{c}\text { Izz, } \\
\text { lbm-in }{ }^{2} \\
\end{array}$ & $\begin{array}{c}\text { IzZ, } \\
\% \text { error }\end{array}$ & $\begin{array}{c}\mathrm{I}_{\mathrm{XY}}, \\
\mathrm{lbm}-\mathrm{in}^{2}\end{array}$ & $\begin{array}{c}\mathrm{IXZ}, \\
\mathrm{lbm}-\mathrm{in}^{2}\end{array}$ & $\begin{array}{c}\text { IXZ, } \\
\% \text { error }\end{array}$ & $\begin{array}{c}\text { IYZ, } \\
\text { lbm-in }\end{array}$ \\
\hline & & & & & & & & $\mathrm{x} 10^{7}$ & & $\mathrm{x} 10^{7}$ & & $\mathrm{x} 10^{7}$ & & $\mathrm{x} 10^{6}$ & $\mathrm{x} 10^{6}$ & & $\mathrm{x} 10^{6}$ \\
\hline 1 & 17,596 & $3.4 \%$ & 89.5 & $-0.6 \%$ & -0.7 & 19.1 & 2. $0 \%$ & 4. 22 & $-2.7 \%$ & 6.02 & $2.3 \%$ & 9.21 & $-5.5 \%$ & -0.59 & -3.78 & $-21.0 \%$ & 0.53 \\
\hline 2 & 17,591 & $3.4 \%$ & 89.5 & $-0.5 \%$ & -0.9 & 19.7 & $5.2 \%$ & 4. 22 & $-2.7 \%$ & 6.00 & $2.0 \%$ & 9.22 & $-5.4 \%$ & -0.64 & -3.70 & $-22.7 \%$ & 0.61 \\
\hline 3 & 17,604 & $3.5 \%$ & 89.6 & $-0.4 \%$ & -0.9 & 19.7 & $5.3 \%$ & 4. 22 & $-2.7 \%$ & 6.00 & 2. $1 \%$ & 9.23 & $-5.2 \%$ & -0.59 & -3.73 & $-21.9 \%$ & 1.02 \\
\hline 4 & 17,187 & $1.0 \%$ & 90.5 & $0.6 \%$ & 1.3 & 18.0 & $-3.8 \%$ & 4. 20 & $-3.3 \%$ & 5.76 & $-2.0 \%$ & 9.53 & $-2.1 \%$ & -0.49 & -3.13 & $-34.5 \%$ & -1.20 \\
\hline 5 & 17,221 & $1.2 \%$ & 90.5 & $0.6 \%$ & 1.1 & 18.9 & $1.3 \%$ & 4. 19 & $-3.5 \%$ & 5.75 & $-2.2 \%$ & 9.53 & $-2.1 \%$ & -0.49 & -3.09 & $-35.3 \%$ & -1.06 \\
\hline 6 & 17,229 & $1.3 \%$ & 90.6 & $0.6 \%$ & 1.0 & 19.0 & $1.6 \%$ & 4. 19 & $-3.5 \%$ & 5.76 & $-2.1 \%$ & 9.54 & $-2.0 \%$ & -0.43 & -3.11 & $-35.0 \%$ & -0.75 \\
\hline 7 & 16,684 & $-1.9 \%$ & 89.4 & $-0.7 \%$ & 2.9 & 10.2 & $-45.3 \%$ & 3.04 & $-30.0 \%$ & 5.83 & $-0.8 \%$ & 7. 60 & $-22.0 \%$ & -3.91 & 9.70 & $-302.8 \%$ & -4.33 \\
\hline 8 & 16,790 & $-1.3 \%$ & 89.3 & $-0.8 \%$ & 2.4 & 12.4 & $-33.7 \%$ & 3.53 & $-18.5 \%$ & 6.23 & $6.0 \%$ & 8.46 & $-13.1 \%$ & -0.90 & 4. 33 & $-190.6 \%$ & 1.29 \\
\hline 9 & 16,653 & $-2.1 \%$ & 89.7 & $-0.3 \%$ & -0.1 & 14.5 & $-22.2 \%$ & 3.42 & $-21.2 \%$ & 6.08 & $3.4 \%$ & 7. 89 & $-19.0 \%$ & -2.52 & 7. 22 & $-251.0 \%$ & -2.94 \\
\hline 10 & 16,595 & $-2.5 \%$ & 90.8 & $0.9 \%$ & 2.4 & 13.6 & $-27.2 \%$ & 3.27 & $-24.6 \%$ & 5.71 & $-2.9 \%$ & 8.58 & $-11.9 \%$ & -2.68 & 4. 96 & $-203.7 \%$ & -4.04 \\
\hline 11 & 15,560 & $-8.5 \%$ & 91.0 & $1.1 \%$ & 1.5 & 17.3 & $-7.6 \%$ & 3. 98 & $-8.3 \%$ & 6. 12 & 4. $1 \%$ & 10.19 & 4. $6 \%$ & 1.81 & -4.69 & $-1.8 \%$ & 4. 42 \\
\hline 12 & 16,176 & $-4.9 \%$ & 91.2 & $1.3 \%$ & 0.0 & 18.0 & $-3.4 \%$ & 3.74 & $-13.7 \%$ & 5.87 & $-0.2 \%$ & 9.12 & $-6.3 \%$ & -0.36 & 0.20 & $-104.2 \%$ & -1.50 \\
\hline
\end{tabular}

\section{Comparison of Results from Three Methods}

Table 9 summarizes the results from analytical, pendulum swings, and DIM methods to find mass properties. Case 1 of the DIM method was used for comparison. The symmetrical geometry of the iron bird made the Ixy and Iyz POI negligible; they were not tested.

Table 9. Summary of mass properties calculations derived by three different methods.

\begin{tabular}{|c|c|c|c|c|c|c|c|c|c|c|c|c|c|c|c|}
\hline $\begin{array}{l}\text { Mass, } \\
\text { lbm }\end{array}$ & $\begin{array}{c}\text { Mass, } \\
\text { error } \\
\end{array}$ & $\begin{array}{c}\mathrm{X}_{\mathrm{CG}}, \\
\text { in }\end{array}$ & $\begin{array}{c}\mathrm{X}_{\mathrm{CG}}, \\
\% \text { error }\end{array}$ & $\begin{array}{c}\mathrm{Y}_{\mathrm{CG}} \\
\text { in } \\
\end{array}$ & $\begin{array}{c}\mathrm{Y}_{\mathrm{CG}}, \\
\% \text { error }\end{array}$ & $\begin{array}{c}\mathrm{Z}_{\mathrm{CG}}, \\
\text { in }\end{array}$ & $\begin{array}{c}Z_{\mathrm{CG}}, \\
\% \text { error }\end{array}$ & $\begin{array}{c}\mathrm{I}_{\mathrm{XX}}, \\
1 \mathrm{bm}-\mathrm{in}^{2}\end{array}$ & $\begin{array}{c}\mathrm{I}_{\mathrm{Xx}}, \\
\% \text { error }\end{array}$ & $\begin{array}{c}\mathrm{I}_{\mathrm{YY}}, \\
\mathrm{lbm}-\mathrm{in}^{2}\end{array}$ & $\begin{array}{c}\mathrm{I}_{\mathrm{YY}}, \\
\% \text { error }\end{array}$ & $\begin{array}{c}\mathrm{I}_{\mathrm{ZZ}}, \\
\mathrm{lbm}-\mathrm{in}^{2}\end{array}$ & $\begin{array}{c}\mathrm{IzZ}_{\mathrm{zZ}} \\
\% \text { error }\end{array}$ & $\begin{array}{c}\mathrm{I}_{\mathrm{XZ}}, \\
\mathrm{lbm}-\mathrm{in}^{2}\end{array}$ & $\begin{array}{c}\mathrm{I}_{\mathrm{Xz}}, \\
\% \text { error }\end{array}$ \\
\hline & & & & & & & & $\mathrm{x} 10^{7}$ & & $\mathrm{x} 10^{7}$ & & $\mathrm{x} 10^{7}$ & & $\mathrm{x} 10^{6}$ & \\
\hline \multicolumn{16}{|c|}{ Analytical } \\
\hline 17012 & - & 90.00 & - & 0.00 & - & 18.69 & - & 4.34 & - & 5.88 & - & 9.74 & - & -4.78 & - \\
\hline \multicolumn{16}{|c|}{ Pendulum swing } \\
\hline 16973 & $-0.2 \%$ & 90.02 & $0 \%$ & -0.03 & - & 18.69 & $0 \%$ & 4. 19 & $-3.5 \%$ & 6.13 & 4. $3 \%$ & 9.52 & $-2.3 \%$ & -9.46 & $-97.9 \%$ \\
\hline \multicolumn{16}{|c|}{ Dynamic Inertia Measurement } \\
\hline 16805 & $-1.2 \%$ & 89.70 & $-0.3 \%$ & -0.20 & - & 18.20 & $-2.6 \%$ & 4. 20 & $-3.2 \%$ & 5.97 & $1.5 \%$ & 9.23 & $-5.2 \%$ & -3.83 & $19.9 \%$ \\
\hline
\end{tabular}

The DIM method yielded results that matched within approximately 5 percent of the analytical iron bird mass, CG, and MOI. The $\mathrm{I}_{\mathrm{xz}}$ POI did not match as well, having with errors exceeding 20 percent, however, the DIM I $\mathrm{I}_{\mathrm{xz}}$ results were still better than the 98-percent error from the pendulum-based testing results due to test setup limitations (that is, shallow tilt angle).

\section{Cost and Labor Comparison}

Labor, time, and equipment costs to find the mass properties of the iron bird test article were compared between the pendulum swing and DIM testing methods. 


\section{A. Labor and Time}

The time and required labor for each activity was recorded in order to provide some basis from which to compare costs. Pre-test planning, design, and preparation time was not tracked.

The iron bird weight and CG operations required four days to complete; this includes time for setup, testing, and teardown. To measure $\mathrm{Z}_{\mathrm{CG}}$, the test article must be tilted in different configurations, requiring additional time and cost. It should be noted that $\mathrm{Z}_{\mathrm{C}}$ testing was not performed on the iron bird because the analytic $\mathrm{CAD} \mathrm{Z}_{\mathrm{CG}}$ of the test article (simple I-beam geometry) was deemed highly reliable. If this assumption is not made, another five days of labor and testing should be budgeted (to acquire a $\mathrm{Z}_{\mathrm{CG}}$ measurement and to perform any additional design work to accommodate the tilting operation).

During the actual testing process, there were many delays due to procurement lead time, non-fitting parts, and laboratory availability. Extensive planning for the concept of operations was also required for each testing procedure, but is not captured in the comparisons below. Assuming no delays, and including setup and teardown time, the conventional weight and CG and pendulum-based testing is estimated to require approximately 30 days.

The time and labor required between pendulum-based testing and the DIM method is compared. Table 10 summarizes the time and labor requirements for weight and CG and pendulum-based testing. Pendulum tests require testing in four different setup configurations: $\mathrm{I}_{\mathrm{xx}}, \mathrm{I}_{\mathrm{yy}}, \mathrm{I}_{\mathrm{zz}}$, and $\mathrm{I}_{\mathrm{xz}}$. In addition, separate MOI tests must be conducted for the MOI fixture only, creating a total of eight separate pendulum tests. In addition, all of the CG and MOI tests require an extensive amount of pre-test planning time during which to write and review procedures in order to ensure safe and effective operations. The time required for these tasks was not tracked.

Table 10. Time and labor costs for the pendulum testing method.

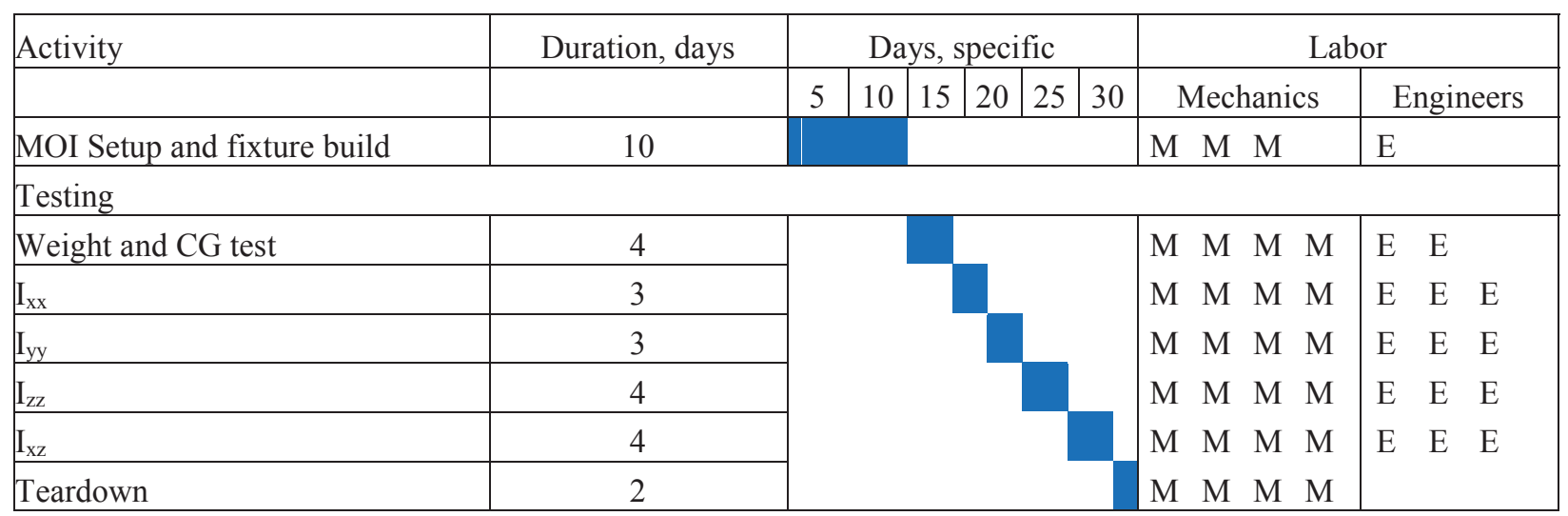

The iron bird DIM test took approximately five days and required setup and teardown time and labor similar to that required for performing a GVT. Table 11 summarizes the time and labor requirements for DIM method testing. Without delays, and including setup and teardown, the DIM test can be estimated to require approximately 15 days. The DIM pre-test planning effort is sufficiently less than that required for proper planning in preparation for eight pendulum testing setups.

Table 11. Time and labor costs for the Dynamic Inertia Measurement testing method.

\begin{tabular}{|c|c|c|c|c|c|c|c|c|c|}
\hline \multirow[t]{2}{*}{ Activity } & Duration, days & \multicolumn{6}{|c|}{ Days, specific } & \multicolumn{2}{|c|}{ Labor } \\
\hline & & 5 & 10 & 15 & 20 & 25 & 30 & Mechanics & Engineers \\
\hline Setup & 6 & & & & & & & $\mathrm{M} M \mathrm{M} \mathrm{N}$ & E E \\
\hline Testing & 5 & & & & & & & $\mathrm{M} M \mathrm{M} \quad \mathrm{N}$ & $\mathrm{E}$ \\
\hline Teardown & 4 & & & & & & & $\mathrm{M} M \mathrm{M} \quad \mathrm{N}$ & E E \\
\hline
\end{tabular}

\section{B. Material Costs}

Costs were broken down to distinguish between one-time costs (to purchase any specialized instrumentation or equipment) and recurring costs (such as sensor calibrations that would be required for each test, assuming each test 
requires recalibration of all sensors). It should be noted that costs are rough approximations and intended to provide a ballpark estimate comparison between methods. Table 12 shows the cost structure definition.

Table 12. Cost structure definition.

\begin{tabular}{|l|l|}
\hline \multicolumn{2}{c}{ Cost structure } \\
\hline$\$$ & $\$ 1-\$ 100$ \\
\hline$\$ \$$ & $\$ 101-\$ 1000$ \\
\hline$\$ \$ \$$ & $\$ 1001-\$ 10000$ \\
\hline$\$ \$ \$$ & $\$ 10001-\$ 100000$ \\
\hline$\$ \$ \$ \$$ & $\$ 100001+$ \\
\hline
\end{tabular}

Table 13 shows the cost estimates for hardware used for the pendulum test.

Table 13. Pendulum test hardware cost estimates.

\begin{tabular}{|l|l|l|l|}
\hline One-time cost & & Recurring costs & \\
\hline Laser tracker & $\$ \$ \$ \$$ & Recalibrate load cells & $\$ \$ \$$ \\
\hline Swing structure & $\$ \$ \$ \$$ & Swing structure assembly & $\$ \$$ \\
\hline Test hardware & $\$ \$ \$$ & Hardware load test & $\$ \$$ \\
\hline Load cells & $\$ \$ \$$ & & \\
\hline IMU (optional) & $\$ \$ \$$ & & \\
\hline
\end{tabular}

Table 14 shows the cost estimates for hardware used for the DIM method test.

Table 14. DIM method test cost estimates.

\begin{tabular}{|c|c|c|c|c|c|}
\hline & One-time costs & & & Recurring Costs (per year) & \\
\hline \multirow{10}{*}{ 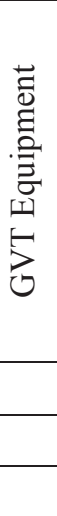 } & DACS & $\$ \$ \$ \$ \$$ & \multirow{3}{*}{8} & Recalibrate Accelerometers and force transducers & $\$ \$ \$$ \\
\hline & Soft supports & $\$ \$ \$ \$$ & & Soft support maintenance & $\$ \$ \$$ \\
\hline & Accelerometers & $\$ \$ \$ \$$ & & Software maintenance & $\$ \$ \$$ \\
\hline & Shakers & $\$ \$ \$$ & & Recalibrate 6-DOFs & $\$ \$ \$ \$$ \\
\hline & Force transducers & $\$ \$ \$$ & & & \\
\hline & Software licenses & $\$ \$ \$$ & & & \\
\hline & Wiring & $\$ \$ \$$ & & & \\
\hline & Laser tracker & $\$ \$ \$ \$ \$$ & & & \\
\hline & 6-DOF force sensors & $\$ \$ \$ \$$ & & & \\
\hline & Seismic accelerometers & $\$ \$ \$$ & & & \\
\hline
\end{tabular}

The equipment required to operate the DIM testing method is more expensive than that required for the pendulum testing method because of the instrumentation necessary to measure the frequency responses during DIM testing. As well, the 6-DOF sensors are custom-designed equipment having a high recurring recalibration cost. Much of the equipment required for DIM testing, however, would already be present and in use for an existing GVT setup. Thus, minimal time would be needed for setup and teardown for DIM testing. The predominant additional costs for DIM testing would likely be that of any necessary 6-DOF force sensors and seismic accelerometers. Hardware on hand naturally also plays a role in reducing the net cost of any testing process. A disadvantage of using GVT equipment to determine vehicle mass properties is the higher risk of lost experimental mass properties data should there be a failure in the GVT equipment. Pendulum methods can provide partial mass properties data and can be reconfigured for other testing configurations should there be any hardware delays or setbacks. 


\section{Recommendations and Considerations}

This iron bird testing series was a successful exercise; however, the DIM method is not a yet a fully mature technology for large aerospace vehicles. ATA Engineering provided the following list of recommendations and considerations for future DIM method tests to further advance the technology readiness level (TRL) of the DIM method on large aerospace vehicles.

\section{A. Testing Recommendations and Considerations}

1. Retest with the iron bird supported on bladder-type air springs instead of the $60 \mathrm{~K} 3 \mathrm{~S}$ system for this test. Using this other type of soft support should eliminate the cluster of modes in the 5- to 8-Hz frequency range and give a broader frequency range over which to estimate the inertia properties.

2. Predict MOI perturbation by adding a mass with known inertia properties to the structure.

\section{B. Processing Recommendations and Considerations}

1. Process the measurements assuming that the accelerometers were mounted in the global coordinate system.

2. Investigate how many accelerometers are sufficient to produce accurate inertia results.

3. Evaluate whether 3-DOF reaction forces are sufficient or 6-DOF reaction forces are necessary.

4. Reformulate inertia equations for known terms (for example, mass, 2 of 3 CG coordinates).

5. Develop a non-subjective procedure to select the "flat spot" in the inertia functions.

6. Develop and explore uncertainty analysis methods for DIM calculations such as a Monte Carlo or Cramer-Rao bounds.

7. Implement spatial filtering with the ATA Engineering IMAT+Signal ${ }^{\mathrm{TM}}$ spVIEW ${ }^{\mathrm{TM}}$ user tools.

\section{Basic Theory Recommendations and Considerations}

1. Perform analysis or modeling to better understand the effects of force path and to explain more completely the differences of exciting on the structure and exciting through the force sensors.

2. Investigate the influence of gravity at low frequency. Is the calibration of the 6-DOF force sensors dependent on the orientation of the calibration mass in the gravitation field? It is known that the output of sensors depends upon orientation, but the current implementation does not compensate for gravity.

\section{Additional Recommendations}

1. Evaluate the effects of the 3-DOF force transducer off-axis reaction forces on the accuracy of the computed mass properties.

2. Investigate the required redundancy for the excitation of the six rigid body modes in relation to the typical multiple-shaker configurations used during GVT.

\section{Conclusions}

The Dynamic Inertia Measurement (DIM) method shows promise for mass properties testing applications involving large aerospace vehicles. There were sources of error that required mitigation; for example, the soft-support system introduced modes into the test data. As well, the DIM method was found to be sensitive to different shaker configurations and test setups. Several recommendations were therefore made with regard to the method of DIM testing.

Performing the DIM method on the "iron bird" test article advanced the maturity level of the method toward future use on full-scale aerospace vehicles. The next step in the maturation of the DIM method would be to apply the technique to a full-scale aerospace vehicle.

Conventional pendulum-based mass properties testing was performed to compare results and level of effort with the DIM method. The pendulum methods created a variety of operational challenges. Several lift procedures and reviews were required to move the iron bird test article into the pendulum-testing configuration due to the safety-critical nature of the setup, and the design of the pendulum test setup itself had many shortcomings. For example, design flaws in the test hardware introduced friction into the test setup that created a frequency shift and deteriorated quality of the data. In spite of these challenges, usable data were collected and used to estimate mass properties.

The iron bird test article was supported on three soft supports that simulated free-free boundary conditions. The rigid body modes were below $2 \mathrm{~Hz}$, and the first flexible mode was above $18 \mathrm{~Hz}$, which was sufficient separation for the DIM method; however, there was a cluster of soft-support modes in the 10- to $17-\mathrm{Hz}$ frequency range. These modes were localized suspension modes having little effect on the calculated inertia functions below $12 \mathrm{~Hz}$. This configuration allowed a maximum 2 - to $12-\mathrm{Hz}$ frequency band from which to estimate inertia and center of gravity 
values. The results were fairly consistent across the six single-shaker test cases, and the relative error compared to analytical values was typically only a few percent, except for the one non-zero product of inertia. The results for the six skewed, double-shaker test cases, however, exhibited greater relative error and larger variance among the test runs. Therefore, in this iron bird case, single-shaker configurations provided the best results.

The DIM mass properties testing method requires expensive sensors and equipment. Fortunately, much of the necessary equipment is already available if ground vibration testing has been performed. Additionally, performing the DIM test can simultaneously provide the same modal characteristics data used for ground vibration testing analysis. After comparing the labor and time needed to perform each test, the DIM test was determined to be capable of experimentally determining mass properties twice as fast as the conventional pendulum method. In addition, the conventional pendulum method contains much higher schedule and vehicle risk, requires more procedural reviews and multiple pieces of specialized hardware and interface frames, and multiple testing configurations. The DIM method, with further development, may prove to be a more efficient approach to estimating the mass properties of a large aerospace vehicle.

\section{Acknowledgements}

The authors thank the NASA Aeronautics Research Mission Directorate Aerosciences Project and Aeronautics Test Program for funding the Dynamic Inertia Measurement research. The authors also thank the testing support at the Flight Loads Laboratory at the Armstrong Flight Research Center for the Dynamic Inertia Measurement and pendulum tests. Special thanks also go to aerospace engineers Bob Clarke and Adam Harding of the Armstrong Flight Research Center for their support and expertise in performing the conventional pendulum mass properties tests.

\section{References}

${ }^{1}$ Toivola, J., and Nuutila, O., "Comparison of Three Methods for Determining Rigid Body Inertia Properties from Frequency Response Functions," Proceedings of the 11th International Modal Analysis Conference, pp. 1126-1132, 1993.

${ }^{2}$ Witter, M. C. , "Rigid Body Inertia Property Estimation Using the Dynamic Inertia Method, Master of Science thesis, Department of Mechanical Engineering, University of Cincinnati, Ohio, 2000.

${ }^{3}$ Lazor, D. R., "Considerations for Using the Dynamic Inertia Method in Estimating Rigid Body Inertia Property," Master's of Science thesis, Department of Mechanical Engineering, University of Cincinnati, Ohio, 2004.

${ }^{4}$ Peterson, W. L., "Mass Properties Measurement in the X-38 Project, SAWE paper no. 3325, category 6, 2004.

${ }^{5}$ Stebbins, M. A., and Brown, D. L., "Rigid Body Inertia Property Estimation Using a Six-axis Load Cell," Proceedings of the 16th International Modal Analysis Conference, pp. 900-906, 1998.

${ }^{6}$ Gatzwiller, K. B., Witter, M. C., and Brown, D. L., "A New Method for Measuring Inertial Properties," Proceedings of the 18th International Modal Analysis Conference, pp. 1056-1062, 2000.

${ }^{7}$ Witter, M. C., Brown, D. L., and Dillon, M., "A New Method for RBP Estimation - The Dynamic Inertia Method," SAWE paper no. 2461, category no. 6, 1999.

${ }^{8}$ Green, M. W., "Measurement of the Moments of Inertia of Full Scale Airplanes," NACA Technical Note No. 265, 1927.

${ }^{9}$ Miller, M. P., "An Accurate Method of Measuring the Moments of Inertia of Airplanes," NACA Technical Note No. 351, 1930.

${ }^{10}$ Miller, M. P., and Soule, H. A., "Moments of Inertia of Several Airplanes," NACA Technical Note No. 375, 1931.

${ }^{11}$ Soule, H. A., and Miller, M. P., "The Experimental Determination of the Moments of Inertia of Airplanes," NACA Report No. 467, 1933.

${ }^{12}$ Turner, H. L., "Measurement of the Moments of Inertia of an Airplane by a Simplified Method," NACA Technical Note 2201, 1950.

${ }^{13}$ Gracey, W., "The additional-mass effect of plates as determined by experiments, NACA Report No, 707, 1941.

${ }^{14}$ Fladung, W. A., Napolitano, K. L., and Brillhart, R. D. , "Final Report on Dynamic Inertia Measurement Method Testing, unpublished internal document, ATA Engineering, San Diego, California, 2010.

${ }^{15}$ Cloutier, D., and Fladung, W. A., "Final Report on Dynamic Inertia Measurement Method Testing on Iron Bird 2," unpublished internal document, ATA Engineering, San Diego, California, 2013.

${ }^{16}$ Holland J. A., "A Safe, Advanced, Adaptable Isolation System that Eliminates the Need for Critical Lifts," NP-2009-08-02-DFRC, http://www. nasa.gov/pdf/484129main_Soft-Support-TOP.pdf [cited November 18, 2014]. 